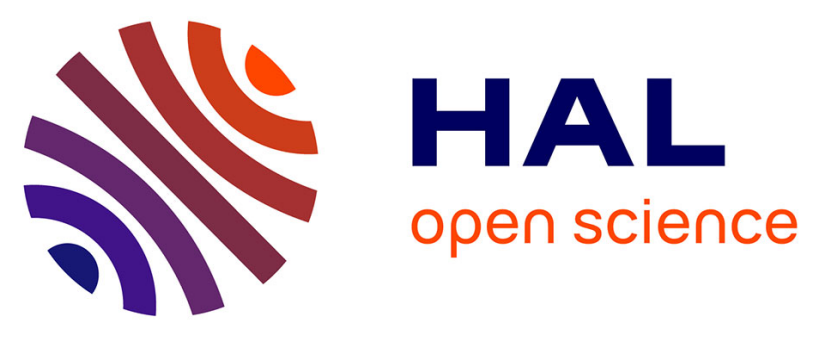

\title{
Experimental and database-transferred electron-density analysis and evaluation of electrostatic forces in coumarin-102 dye
}

\author{
Yvon Bibila Mayaya Bisseyou, Nouhza Bouhmaida, Benoit Guillot, Claude \\ Lecomte, Noël Lugan, Noureddine Ghermani, Christian Jelsch
}

\section{To cite this version:}

Yvon Bibila Mayaya Bisseyou, Nouhza Bouhmaida, Benoit Guillot, Claude Lecomte, Noël Lugan, et al.. Experimental and database-transferred electron-density analysis and evaluation of electrostatic forces in coumarin-102 dye. Acta Crystallographica Section B : Structural Science [1968-2013], 2012, 68 (6), pp.646-660. 10.1107/S0108768112042826 . hal-01710505

\section{HAL Id: hal-01710505 \\ https://hal.science/hal-01710505}

Submitted on 16 Feb 2018

HAL is a multi-disciplinary open access archive for the deposit and dissemination of scientific research documents, whether they are published or not. The documents may come from teaching and research institutions in France or abroad, or from public or private research centers.
L'archive ouverte pluridisciplinaire HAL, est destinée au dépôt et à la diffusion de documents scientifiques de niveau recherche, publiés ou non, émanant des établissements d'enseignement et de recherche français ou étrangers, des laboratoires publics ou privés. 


\section{Experimental and database-transferred electron-density analysis and evaluation of electrostatic forces in coumarin-102 dye}

\section{Yvon Bibila Mayaya Bisseyou, Nouhza Bouhmaida, Benoit Guillot, Claude Lecomte, Noel Lugan, Noureddine Ghermani and Christian Jelsch}

Acta Cryst. (2012). B68, 646-660

Copyright (C) International Union of Crystallography

Author(s) of this paper may load this reprint on their own web site or institutional repository provided that this cover page is retained. Republication of this article or its storage in electronic databases other than as specified above is not permitted without prior permission in writing from the IUCr.

For further information see http://journals.iucr.org/services/authorrights.html

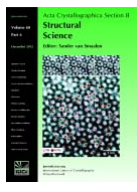

Acta Crystallographica Section B: Structural Science publishes papers in structural chemistry and solid-state physics in which structure is the primary focus of the work reported. The central themes are the acquisition of structural knowledge from novel experimental observations or from existing data, the correlation of structural knowledge with physicochemical and other properties, and the application of this knowledge to solve problems in the structural domain. The journal covers metals and alloys, inorganics and minerals, metal-organics and purely organic compounds.

Crystallography Journals Online is available from journals.iucr.org 
Acta Crystallographica Section B

Structural

Science

ISSN 0108-7681

Yvon Bibila Mayaya Bisseyou, ${ }^{\text {a,b }}$ Nouhza Bouhmaida, ${ }^{\mathrm{c}}$ Benoit Guillot, ${ }^{\text {a }}$ Claude Lecomte, ${ }^{\mathrm{a}}$ Noel Lugan, ${ }^{d}$ Noureddine Ghermani ${ }^{e, a}$ and Christian Jelsch ${ }^{\mathrm{a} *}$

a Laboratoire de Cristallographie, Résonance Magnétique et Modélisations $\left(\mathrm{CRM}^{2}\right), \mathrm{CNRS}$, UMR 7036, Institut Jean Barriol, Faculté des Sciences et Technologies, Université de Lorraine, BP 70239, 54506 Vandoeuvre-lèsNancy CEDEX, France, ${ }^{\mathbf{b}}$ Laboratoire de Cristallographie et Physique Moléculaire, UFR SSMT, Université de Cocody, 22 BP 582 Abidjan 22, Ivory Coast, ' ${ }^{\mathrm{LSSM}}$, Laboratoire des Sciences des Matériaux, Université Cadi Ayyad, Faculté des Sciences Semlalia, Boulevard Prince Moulay Abdallah, BP 2390, 40000 Marrakech, Morocco, ${ }^{\mathbf{d}} \mathrm{CNRS}$, LCC (Laboratoire de Chimie de Coordination), 205 route de Narbonne, 31077 Toulouse CEDEX 4, France, and ${ }^{\mathbf{e}} \mathrm{PPB}$, Laboratoire Physico-Chimie-PharmacotechnieBiopharmacie, UMR CNRS 8612, Université Paris-Sud 11, Faculté de Pharmacie, 5 rue JeanBaptiste Clément, 92296 Châtenay-Malabry, France

Correspondence e-mail:

christian.jelsch@univ-lorraine.fr

\section{Experimental and database-transferred electron- density analysis and evaluation of electrostatic forces in coumarin-102 dye}

The electron-density distribution of a new crystal form of coumarin-102, a laser dye, has been investigated using the Hansen-Coppens multipolar atom model. The charge density was refined versus high-resolution X-ray diffraction data collected at $100 \mathrm{~K}$ and was also constructed by transferring the charge density from the Experimental Library of Multipolar Atom Model (ELMAM2). The topology of the refined charge density has been analysed within the Bader 'Atoms In Molecules' theory framework. Deformation electron-density peak heights and topological features indicate that the chromen-2-one ring system has a delocalized $\pi$-electron cloud in resonance with the $\mathrm{N}$ (amino) atom. The molecular electrostatic potential was estimated from both experimental and transferred multipolar models; it reveals an asymmetric character of the charge distribution across the molecule. This polarization effect is due to a substantial charge delocalization within the molecule. The molecular dipole moments derived from the experimental and transferred multipolar models are also compared with the liquid and gas-phase dipole moments. The substantial molecular dipole moment enhancements observed in the crystal environment originate from the crystal field and from intermolecular charge transfer induced and controlled by $\mathrm{C}-\mathrm{H} \cdots \mathrm{O}$ and $\mathrm{C}-\mathrm{H} \cdots \mathrm{N}$ intermolecular hydrogen bonds. The atomic forces were integrated over the atomic basins and compared for the two electron-density models.

\section{Introduction}

Coumarin derivatives substituted at the 7-position with an amino group, namely 7-aminocoumarins, are well known to display fluorescence (Drexhage, 1973). They form a class of excellent laser dyes in the blue and green regions and display a very high fluorescence quantum yield, sometimes close to unity (Fletcher \& Bliss, 1978; Jones et al., 1980, 1994; Atkins \& Bliss, 1978; Tuccio et al., 1973; Marling et al., 1974; Reynolds \& Drexhage, 1973). Due to their high fluorescence, they have been used as optical brighteners and fluorescence probes.

However, the quantum yield as well as the fluorescence lifetime of these 7-aminocoumarins in polar solvents depends on the amino group flexibility. Indeed it has been shown that the mobility of the amino group reduces significantly the fluorescence efficiency of these dyes in polar solvents (Reynolds \& Drexhage, 1973; Jones et al., 1985). Hence, when the amino group is structurally rigid, the corresponding 7aminocoumarin dyes display a high quantum yield of fluorescence in these same polar solvents.
Received 2 March 2012 Accepted 12 October 2012 


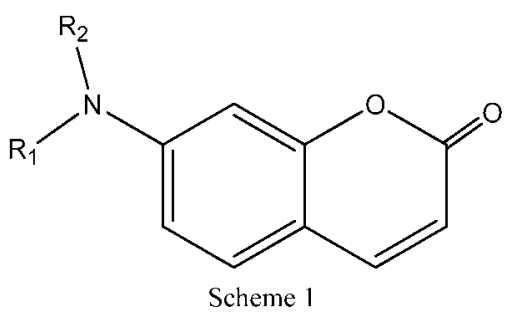

Several other studies were reported on the behaviour of 7aminocoumarin dyes in polar and non-polar solvents (Jones et al., 1985; Nad \& Pal, 2001; Nad et al., 2003; Senthilkumar et al., 2004; Barik et al., 2005). These studies revealed that the loss of the fluorescence efficiency of non-rigid 7-aminocoumarin dyes (Scheme 1) in polar solvents is due to the formation of a twisted intramolecular charge transfer (TICT) state. This TICT state is generated in two stages. The first one involves the formation of an intramolecular charge transfer (ICT) structure (Scheme 2), in which the 7-N-alkyl group and the chromen-2-one moiety are coplanar, and the amino group $\mathrm{N}$ atom electron lone pair is in resonance with the chromen-2one $\pi$ cloud. This step is followed by a rotation of $90^{\circ}$ of the 7 $N$-alkyl group with respect to the chromen-2-one moiety.

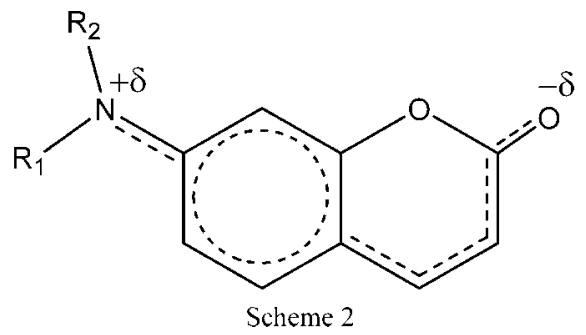

The formation of an ICT structure has also been postulated for structurally rigid 7-aminocoumarin dyes such as coumarin102 (C-102, Scheme 3) and coumarin-153 (Gustavsson et al., 1998; Morlet-Savary et al., 2001), in which the chromen-2-one ring system and the amino atom are also coplanar.

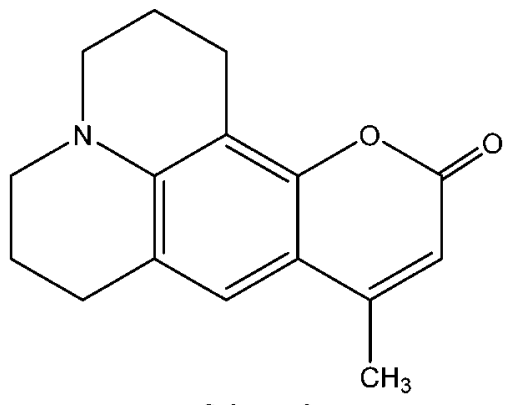

Scheme 3

Besides, the search for clean and low-cost electrical energy revealed that 7-aminocoumarin derivatives constitute one of the most promising dye sources used in the manufacturing of photovoltaic dye-sensitizer-based solar cells (Hara et al., 2001; Hara, Sato et al., 2003; Hara, Tachibana et al., 2003; Wang et al., 2005). These photovoltaic cells (dye-sensitized solar cells) are a kind of photoelectrochemical solar cell composed of a nanostructured mesoporous oxide semiconductor layer and dye sensitizer attached to the surface. The efficiency of a solar cell is estimated through parameters like the open-circuit voltage, $V_{\mathrm{oc}}$, and the short-circuit current density, $J_{\mathrm{sc}}$. These parameters are not only related to the molecular and electronic structure of the valence (HOMO) and the conduction (LUMO) bands of the material constituting the core of the photovoltaic device, but also in the ability of the dye-sensitizer to inject electrons into the conduction band of the semiconductor which acts as a sponge for the dye-sensitizer. The 7aminocoumarin dye-sensitizers in photovoltaic devices exhibit their electron injector role in the solid state. It is then important to understand the phenomenon that governs the process of charge transfer within these dye-sensitizers in this state.

In the literature there are several reports on coumarin charge-density analyses (Howard et al., 2009; Munshi \& Guru Row, 2005, 2006). In the case of 7-aminocoumarins dyes, several structural analyses have been reported (Chinnakali $e t$ al., 1989, 1990a,b,c, 1992; Chinnakali, Selladurai et al., 1990; Selladurai \& Subramanian, 1992; Yip, Fun et al., 1995; Yip, Yaw et al., 1995; Yip et al., 1996; Honda et al., 1996; Jasinski \& Woudenberg, 1994, 1995) and only one investigation on charge-density determination was performed (Munshi et al., 2010). Examination of the results of structural studies on the 7 -aminocoumarin dyes quoted above shows that the amino group is in the plane of the chromen-2-one ring system. Hence, we can also expect the formation of an ICT structure in the crystal environment. Therefore, a study of the precise electron-density distribution within 7 -aminocoumarins dyes in the crystal state will bring precious information on electrondensity distribution and on intra- and intermolecular interactions in those molecules.

Charge-density analysis based on sub-atomic resolution Xray diffraction data collected at low temperature constitutes an effective tool for such a study. It allows modelling the charge-density distribution of molecules in the crystal environment, and also characterization of chemical interactions such as covalent and hydrogen bonds. Furthermore, interatomic or intermolecular charge transfer can be accurately quantified.

The present crystal structure of C-102 is a polymorphic form of that previously reported by Chinnakali et al. (1990c). The charge-density distribution was analyzed (i) from a refinement against experimental data and (ii) from the experimental library of multipolar atom models (ELMAM2; Domagała $e t$ al., 2011). The original ELMAM library (Pichon-Pesme et al., 2004; Zarychta et al., 2007) was the first experimental database of peptide and amino-acid fragments ever constructed, based on the Hansen-Coppens (Hansen \& Coppens, 1978) multipolar formalism. It was updated later onto the ELMAM2 database and was extended from atom types encountered in proteins to common organic molecules. In addition, it is now based on the optimal local coordinate systems described in Domagała \& Jelsch (2008). The topological properties of the charge-density distribution and molecular electrostatic potential analysis have also been performed. 
Table 1

Summary of diffraction data collection and crystallographic refinement statistics.

\begin{tabular}{|c|c|c|c|c|}
\hline & \multicolumn{3}{|l|}{ Present study } & Chinnakali et al. $(1990 c)$ \\
\hline \multicolumn{5}{|l|}{ Crystal data } \\
\hline Chemical formula & & $\mathrm{C}_{16} \mathrm{H}_{17} \mathrm{NO}_{2}$ \\
\hline$M_{\mathrm{r}}$ & 255.30 & & & $\begin{array}{l}255.30 \\
P 2_{1} / a\end{array}$ \\
\hline Temperature $(\mathrm{K})$ & 100 & \multicolumn{2}{|l|}{296} & $\begin{array}{l}P 2_{1} / a \\
296\end{array}$ \\
\hline Unit cell $a, b, c(\AA)$ & $8.5755(3), 10.1627(3), 14.2676(2)$ & \multicolumn{2}{|c|}{$8.6446(12), 10.2338(7), 14.5037$ (19) } & 8.253 (2) 15.660 (7) 10.112 (4) \\
\hline$\beta\left({ }^{\circ}\right)$ & $95.249(2)$ & \multicolumn{2}{|c|}{$96.636(13)$} & $95.82(3)$ \\
\hline$V\left(\AA^{3}\right)$ & $1238.21(1)$ & \multicolumn{2}{|c|}{$1274.5(3)$} & $1300.2(6)$ \\
\hline \multicolumn{5}{|l|}{ Data collection } \\
\hline Diffractometer & \multicolumn{3}{|c|}{ Oxford Diffraction Xcalibur four-circle } & Rigaku AFC5R \\
\hline Absorption correction & \multicolumn{3}{|l|}{ Analytical } & None \\
\hline$T_{\min }, T_{\max }$ & \multicolumn{3}{|l|}{$0.943,0.975$} & - \\
\hline $\begin{array}{l}\text { No. of measured, independent and } \\
\text { observed }[I>2.0 \sigma(I)] \text { reflections }\end{array}$ & \multicolumn{3}{|l|}{$77717,12801,9801$} & $-, 1387,-$ \\
\hline & Present study & & & Chinnakali et al. (1990c) \\
\hline Scattering factor & Spherical & Multipolar & ELMAM2 & Spherical \\
\hline & H_iso & H_aniso & H_aniso & H_iso \\
\hline $\sin (\theta / \lambda)_{\max }\left(\AA^{-1}\right)$ & 0.7 & 1.09 & 1.09 & 0.99 \\
\hline No. of data with $I / \sigma(I)>2$ & 3459 & 9849 & 9849 & 1020 \\
\hline No. of variables & 173 & 818 & 225 & - \\
\hline Goodness-of-fit (g.o.f.) & 0.925 & 1.01 & 1.06 & - \\
\hline$R(F)$ & 0.036 & 0.037 & 0.038 & 0.065 \\
\hline$w R^{2}(F)$ & 0.104 & 0.024 & 0.026 & 0.071 \\
\hline $\begin{array}{l}\text { Largest residual electron density } \\
\text { hole and peak }\left(\mathrm{e} \AA^{-3}\right)\end{array}$ & $-0.33,0.31$ & $-0.23,0.37$ & $-0.25,0.41$ & \\
\hline
\end{tabular}

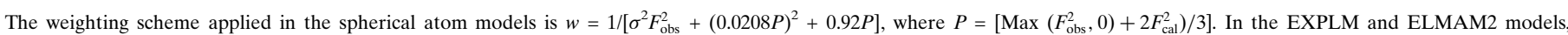
$w=7 /\left[\sigma^{2}\left(F_{\text {obs }}\right)\right]$.

\section{Materials and methods}

\subsection{Experimental part}

The pale yellow crystalline powder of Coumarin-102 was purchased from Sigma and dissolved in acetone. Parallelepiped-shaped single crystals of pale yellow color were obtained by slow evaporation at room temperature.

A diamond-shaped yellow crystal of dimensions $0.33 \times 0.65$ $\times 0.91 \mathrm{~mm}$ was mounted on an Oxford Diffraction Xcalibur four-circle diffractometer equipped with a Sapphire CCD detector and an Oxford Diffraction Cryojet $\mathrm{N}_{2}$ gas stream lowtemperature device. Graphite-monochromated Mo $K \alpha$ radiation $(\lambda=0.71069 \AA)$ was used $(0.6 \mathrm{~mm}$ collimated) with a generator working at $50 \mathrm{kV}$ and $40 \mathrm{~mA}$. The crystal was cooled from 273 to $100 \mathrm{~K}$ with a mean temperature gradient of $-2 \mathrm{~K} \mathrm{~min}^{-1}$. The detector was kept at a distance of $55 \mathrm{~mm}$ from the crystal and the data were collected by the $\omega$-scan method (frame width $\Delta \omega=0.70^{\circ}$ ) within the limits $0<2 \theta<$ $102.6^{\circ}\left[(\sin \theta / \lambda)_{\max }=1.09 \AA^{-1}\right]$. Three different positions for the detector arm were used $\left(\theta_{\mathrm{d}}=30^{\circ}, 6\right.$ sets of $\omega$ runs, 984 frames, $10 \mathrm{~s}$ per frame; $\theta_{\mathrm{d}}=55^{\circ}, 5$ sets of $\omega$ runs, 647 frames, 30 s per frame; $\theta_{\mathrm{d}}=75^{\circ}, 7$ sets of $\omega$ runs, 1160 frames, 60 s per frame).
The frames were integrated using the CrysAlis Red software package (Oxford Diffraction, 2009b). The MOVIE program (Oxford Diffraction, 2009a) was used to model the shape of the crystal in order to perform a numerical absorption correction procedure. The calculated minimum and maximum transmission coefficients were $T_{\min }=0.943$ and $T_{\max }=0.975$ (Clark \& Reid, 1995). A total of 77717 observed reflections were merged into 13915 unique reflections up to a resolution of $\sin \theta / \lambda=1.09 \AA^{-1}$ in the $2 / m$ Laue group with SORTAV (Blessing, 1989). This data set provided $98.5 \%$ of the data up to $\sin \theta / \lambda=1.09 \AA^{-1}\left(100 \%\right.$ up to $\left.\sin \theta / \lambda=1.00 \AA^{-1}\right)$.

The systematic errors due to the larger crystal size compared with the collimated beam were corrected by refining a scale factor for each diffraction frame. The advantages (fast data collection, higher diffraction intensities) and drawbacks of a large size crystal have been discussed by Görbitz (1999).

The C-102 crystal contains only light atoms $(\mathrm{H}, \mathrm{C}, \mathrm{O}, \mathrm{N})$ and the minimum and maximum transmission factors differ by only $3.3 \%$ (Table 1). Although the shape of the selected crystal was highly anisotropic, the low internal agreement factor $\left(R_{\text {int }}=0.016\right.$, average redundancy $=3.6$ up to $\left.1.09 \AA^{-1}\right)$ supports the good quality and consistency of the C-102 merged data set. In general, the use of a crystal which is too large with respect to the X-ray beam is however not recommended, 
despite most systematic errors being corrected for. This is particularly the case in charge-density analysis, where tiny details in the valence density distribution are studied; these effects can be smaller than the corrections required to take the changing crystal volume into account. Other crystallographic and data collection details are given in Table 1.

The crystal structure of C-102 was solved in the space group $P 2_{1} / n$ by direct methods using SIR 92 software (Altomare et al., 1994) and refined in the spherical atom approximation (based on $F^{2}$ ) by full-matrix least-squares with SHELXL97 (Sheldrick, 2008; Table 1).

The electron-density refinements were performed with the MoPro program (Guillot et al., 2001; Jelsch et al., 2005), which uses the Hansen \& Coppens (1978) multipolar atom formalism (Coppens, 1997). The core and valence spherical electron densities were derived from the relativistic Dirac-Fock wavefunctions of Su \& Coppens (1997). Anomalous dispersion coefficients were taken from Kissel et al. (1995). For non $\mathrm{H}$-atoms, a multipolar description up to the octupolar level ( $l$ $=3$ ) was used, while a dipole $(l=1)$ was applied to all $\mathrm{H}$ atoms. The Slater (1932) functions and charge-density parameters are described in the CIF file.

\subsection{Experimental multipolar refinement}

A complete standard strategy for electron-density refinement, as implemented in MoPro, was performed, starting from the spherical-atom model structure. As low-resolution electron-density features remained in the Fourier residual map, an extinction coefficient was refined which solved the problem. The strategy included a high-order refinement of positional and anisotropic displacement parameters for non- $\mathrm{H}$ atoms. $\mathrm{H}$ atom isotropic displacement parameters were restrained to be $r$ times larger than those of their bonded atoms, with $r=1.5$ for $\mathrm{H}$ atoms belonging to the $\mathrm{CH}_{3}$ group and $r=1.2$ for $\mathrm{CH}_{2}$ and $\mathrm{CH}$ groups. The covalent bond lengths for $\mathrm{H}$ atoms were restrained to the average value observed by neutron diffraction (Allen et al., 1987), with a restraint standard deviation of $0.002 \AA$. Chemically equivalent $\mathrm{H}$ atoms were constrained to have the same set of $\kappa$ parameters.

Anisotropic displacement parameters for the $\mathrm{H}$ atoms were estimated using the SHADE2 (Madsen, 2006) web server and kept fixed at these values yielding the EXPML model.

The calculations of Fourier, deformation and Laplacian electron-density maps were performed with the VMoPro properties calculation tool and the MoProViewer visualization package (Guillot, 2011).

\subsection{Database transfer}

A total number of 16 unique atom types from the extended ELMAM2 database were assigned to 36 atoms of C-102. In the ELMAM2 database the electron density of the non-H atoms was described up to octapolar level, while for $\mathrm{H}$ atoms it was described only using the bond-directed dipole $\left(d_{\mathrm{z}}\right)$ and

\footnotetext{
1 Supplementary data for this paper are available from the IUCr electronic archives (Reference: GW5019). Services for accessing these data are described at the back of the journal.
}

quadrupole $\left(q_{3 z^{2}-1}\right)$ components along with the monopole function.

As the transfer procedure also involves atomic valence populations, a discrepancy with respect to the expected formal charge of the molecule can occur. In the present study, after transfer, the resulting excess charge for C-102 was $+0.301 \mathrm{e}$, corresponding to only +0.0083 e per atom, on average. The molecule was then neutralized by applying a constant charge shift to all atoms, including hydrogen. Subsequently, the transferred charge-density parameters were kept fixed while the scale factor, atomic positions and non-hydrogen ADPs were refined against experimental data, yielding the ELMAM2 model.

\subsection{Electrostatic potential, field and derived properties}

The electrostatic potential $\Phi(\mathbf{r})$ displayed here is calculated using the direct integration method

$$
\Phi(\mathbf{r})=\sum_{j}^{N} \frac{Z_{j}}{\left|\mathbf{r}-\mathbf{R}_{j}\right|}-\int \frac{\rho_{\text {atom } j}\left(\mathbf{r}^{\prime}\right)}{\left|\mathbf{r}-\mathbf{R}_{j}-\mathbf{r}^{\prime}\right|} \mathrm{d} \mathbf{r}^{\prime} .
$$

The summation $j$ is extended to the $N$ atoms of the molecule. $\mathbf{R}_{j}$ and $Z_{j}$ are the position and the nuclear charge of the $j$ th atom, respectively (Stewart, 1982; Weber \& Craven, 1990; Volkov et al., 2006; Ghermani et al., 1993). Starting from the electrostatic formula, $\mathbf{E}(\mathbf{r})=-\nabla \Phi(\mathbf{r})$, where $\mathbf{E}$ is the electric field vector, we have implemented the calculation of the electrostatic field using ELECTROS (Ghermani et al., $1992 a, b, c)$. As for the potential, the electrostatic field contains the nuclear contribution. Both the electrostatic potential and field are non-local properties exhibiting the nucleophilic and electrophilic regions of a molecule and thus are very useful for understanding its chemical reactivity (Bouhmaida et al., 2002; Novaković et al., 2007).

The integrations were performed on atomic basins which are obtained from the topological analysis of the total electron density, based on the atoms in molecules (AIM) theory (Bader, 1990; Henkelman et al., 2006). Therefore, given an atomic surface $S$, one can easily derive atomic charges (Volkov et al., 2000) from the flux of the electric field through the equation

$$
Q=\int_{s} \mathbf{E} \cdot \mathbf{n} \mathrm{d} S
$$

where $\mathbf{n}$ is the normal to the surface at any point.

Moreover, the Maxwell stress tensor $\sigma_{\mathrm{M}}$ can be introduced as the classical component of the quantum stress tensor. The former is expressed as

$$
\begin{aligned}
\sigma_{\mathrm{M}}(\mathbf{r}) & =\left(\begin{array}{ccc}
E_{x}^{2} & E_{x} E_{y} & E_{x} E_{z} \\
E_{x} E_{y} & E_{y}^{2} & E_{y} E_{z} \\
E_{x} E_{z} & E_{y} E_{z} & E_{z}^{2}
\end{array}\right)-\frac{E^{2}}{2}\left(\begin{array}{ccc}
1 & 0 & 0 \\
0 & 1 & 0 \\
0 & 0 & 1
\end{array}\right) \\
& =E(\mathbf{r}) \otimes E(\mathbf{r})-\frac{E^{2}(\mathbf{r})}{2} \delta^{(3)}
\end{aligned}
$$

where $E_{x}, E_{y}$ and $E_{z}$ are the components of the electric field in an orthonormal basis and $E^{2}=E_{x}^{2}+E_{y}^{2}+E_{z}^{2}$ is the modulus 
squared. $\delta^{(3)}$ is the third-order identity tensor. For clarity, $\sigma_{\mathrm{M}}$ is multiplied by $4 \pi$.

Starting from an atomic volume $A$ we have shown in earlier works (Bouhmaida \& Ghermani, 2008; Bouhmaida et al., 2009) that the resulting force acting on an atom is expressed as the flux of the Maxwell tensor through the surface delimiting the atomic volume and thus we have

$$
F(A)=\int_{S} \sigma_{\mathrm{M}}(\mathbf{r}) \mathbf{n} \mathrm{d} S .
$$

The total electrostatic force obtained here is the sum of the Feynman and the Ehrenfest forces. The former is acting on the nucleus and the latter is acting on the electrons (Bader, 1990, 2007; Hernández-Trujillo et al., 2007; Bouhmaida \& Ghermani, 2008). For molecules in a stationary state, the molecular envelope Ehrenfest force is vanishing. However, the Ehrenfest forces acting on atoms in a molecule are dominant and balance each other, leading to molecular cohesion. For molecules at equilibrium, the Feynman force on each nucleus should be zero. The latter condition is usually not satisfied when experimental electron density is used (Bouhmaida \& Ghermani, 2008, and references therein).

The atomic surface considered here delimits the volume, as defined by Bader (1990). For both charges- and forces-derived electrostatic field calculations, the BADERWIN program (Sanville et al., 2007) was used. The program provides the volume of each atom in a separate file, which is very useful to define the atomic surface. In our approach, the surface $S$ of each atom in the molecule is defined as a cloud of points corresponding to a particular cut-off of the electron density. The surface is then triangulated using a Delaunay triangulation method implemented in the GHS3D program (Gamma Project, INRIA, Rocquencourt, France). The flux is calculated numerically.

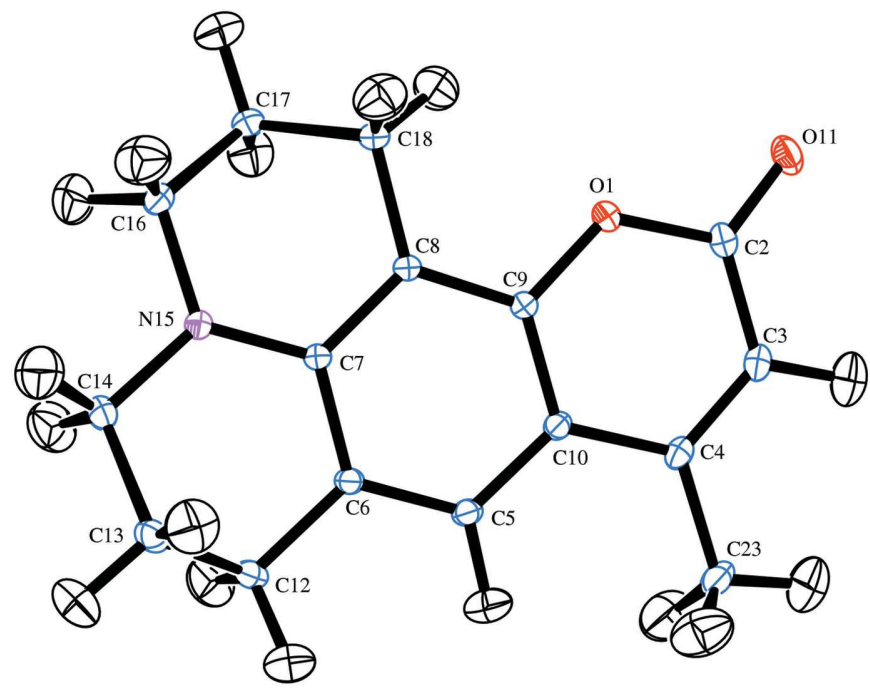

Figure 1

ORTEP view (Farrugia, 1997) of the C-102 dye molecular structure and atomic numbering scheme. Anisotropic displacement ellipsoids of all atoms are drawn at the $50 \%$ probability level. $\mathrm{H}$-atom numbering is omitted for clarity.
Table 2

Selected dihedral angles $\left(^{\circ}\right)$ in the present and in the Chinnakali et al. (1990c) crystal forms.

\begin{tabular}{lrr}
\hline Dihedral angles & \multicolumn{1}{c}{ Present } & Chinnakali \\
\hline C6-C7-N15-C16 & $-173.89(2)$ & $-169.2(5)$ \\
C8-C7-N15-C16 & $5.55(2)$ & $13.0(7)$ \\
C8-C7-N15-C14 & $-169.91(2)$ & $170.2(5)$ \\
C13-C14-N15-C7 & $16.14(2)$ & $33.4(4)$ \\
C7-N15-C16-C17 & $22.17(2)$ & $-41.8(6)$ \\
C14-N15-C7-C6 & $10.64(2)$ & $-12.1(7)$ \\
C12-C13-C14-N15 & $-51.35(2)$ & $-46.4(8)$ \\
N15-C16-C17-C18 & $-52.77(2)$ & $57.7(6)$ \\
C6-C12-C13-C14 & $60.39(2)$ & $37.3(8)$ \\
N15-C7-C6-C12 & $0.39(2)$ & $3.0(7)$ \\
C18-C8-C7-N15 & $-0.95(2)$ & $0.2(7)$ \\
C16-C17-C18-C8 & $55.74(2)$ & $-44.4(6)$ \\
C7-C6-C12-C13 & $-36.04(2)$ & $-15.4(8)$ \\
C17-C18-C8-C7 & $-30.09(2)$ & $16.2(6)$ \\
\hline
\end{tabular}

A sharing surface between two adjacent atoms can be obtained. The flux of the electric field through this interatomic surface leads to interatomic forces (Chambrier et al., 2011). One focus of this paper is the calculation of the atomic charges and the quantification of the total atomic electrostatic forces moduli, as well as the interatomic forces. The latter is projected onto the bond line to estimate its magnitude. These force calculations are performed on the coumarin molecule C102 from the EXPML and ELMAM2 library of electrondensity parameters for comparison.

\section{Results and discussion}

\subsection{Molecular and crystal structure}

The crystallographic data and statistics, as well as the leastsquares refinements details are listed Table 1 together with those obtained by Chinnakali et al. (1990c) at room temperature on the other crystal form. Both polymorphs crystallize in similar monoclinic systems with the same $Z=4$ (the structures were solved in space groups $P 2_{1} / n$ in the present study and $P 2_{1} / a$ in the other form). The ORTEP diagram of atomic anisotropic displacement ellipsoids along with numbering scheme for the present structure at $100 \mathrm{~K}$ is displayed in Fig. 1. The bond lengths and angles involving non$\mathrm{H}$ atoms are listed in the supplementary materials (Table S3). The dihedral angles of the julolidyl ring system are reported in Table 2 for both polymorphic structures. In the new structure the chromen-2-one moiety is planar and both piperidine ring systems adopt a flattened half-chair conformation, as earlier reported by Chinnakali et al. (1990c). Slightly increased covalent bond lengths are observed, on average, in the present polymorphic structure at $100 \mathrm{~K}$, the largest discrepancy being $0.068 \AA$ for the $\mathrm{C} 13-\mathrm{C} 14$ bond.

In addition, the comparison analysis of dihedral angles in both structures clearly shows that the julolidyl ring system has different conformations. In the other polymorph the julolidyl ring displays an anti conformation, whereas in the current structure at room temperature this ring system has a syn conformation. The existence of two distinct conformations of 
Table 3

Hydrogen bonds revealed from geometric characteristics using the PLATON program (Spek, 2003).

\begin{tabular}{lllll}
\hline$D-\mathrm{H} \cdots A$ & $D-\mathrm{H}(\AA)$ & $\mathrm{H} \cdots A(\AA)$ & $D \cdots A(\AA)$ & $D-\mathrm{H} \cdots A\left(^{\circ}\right)$ \\
\hline $\mathrm{C} 5-\mathrm{H} 5 \cdots \mathrm{O} 11^{\mathrm{i}}$ & 1.08 & 2.38 & $3.4189(4)$ & 161 \\
$\mathrm{C} 17-\mathrm{H} 17 B \cdots \mathrm{O} 11^{\mathrm{ii}}$ & 1.09 & 2.48 & $3.4620(4)$ & 149 \\
$\mathrm{C} 23-\mathrm{H} 23 A \cdots \mathrm{O} 11^{\mathrm{iii}}$ & 1.06 & 2.55 & $3.5901(4)$ & 169 \\
\hline
\end{tabular}

Symmetry codes: (i) $\quad x+\frac{1}{2},-y+\frac{3}{2}, z+\frac{1}{2} ; \quad$ (ii) $\quad-x+\frac{3}{2}, y-\frac{1}{2}, z-\frac{1}{2}$; $\quad$ (iii) $-x+\frac{3}{2}, y+\frac{1}{2},-z-\frac{1}{2}$.

the julolidyl ring system in the two structures provides evidence that the two crystal structures are conformational polymorphs. The molecular crystal-packing arrangements illustrated in Fig. 2 show distinct orientations of the molecules in the two crystal forms. In the other polymorph, molecules stack in head-to-head and tail-to-tail fashions along the $c$ axis (Fig. 2a). On the other hand, in the current packing (Fig. 2b) the molecules stack along the $b$ axis in a head-to-tail fashion. The molecules also form extended surface head-to-tail $\pi-\pi$ interactions along the $a$ axis.

A view of the crystal packing, illustrated in Fig. 3(a), displays three intermolecular $\mathrm{C}-\mathrm{H} \cdots \mathrm{O}$ interactions, identified as hydrogen bonds from PLATON (Spek, 2003). The carbonyl $\mathrm{O} 11$ atom acts as an acceptor in these $\mathrm{C}-\mathrm{H} \cdots \mathrm{O}$ hydrogen bonds (Table 3). These hydrogen bonds contribute to the consolidation of crystal packing via the formation of double molecular chains, as shown in Fig. 3(b).

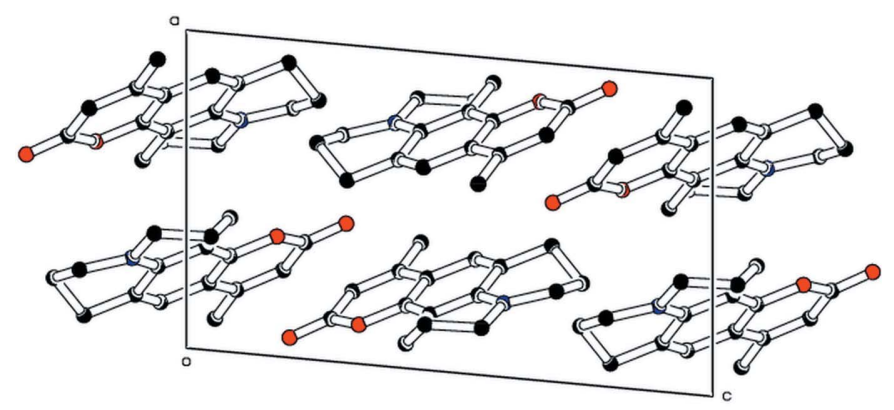

(a)

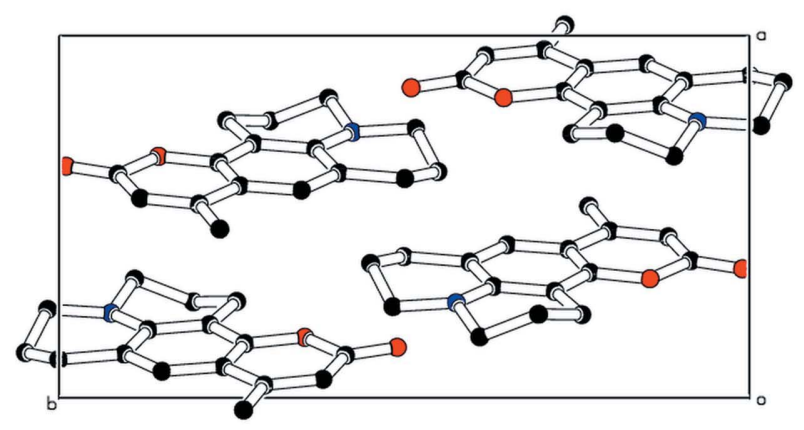

(b)

Figure 2

Molecular packing diagrams showing the orientation of C-102 molecules in the two polymorphic crystal forms. $\mathrm{H}$ atoms are omitted for clarity. (a) View down the $\mathbf{b}$ axis of the crystal form found by Chinnakali et al. (1990c); (b) view down the $\mathbf{c}$ axis of the present crystal form.
The unit cell of the crystal (Table 1) was also measured at room temperature to compare the crystal compactness with the other crystal forms published by Chinnakali et al. (1990). At room temperature the current crystal form is slightly more compact with a $2.0 \%$ reduction of the unit-cell volume. The volume decrease from room to cryogenic temperature reaches $2.8 \%$. By comparison, there is a similar unit cell shrinking for coumarin 314, orange and yellow crystal forms (Munshi et al., 2010 ), of 2.4 and $2.9 \%$ from room temperature to $100 \mathrm{~K}$.

\subsection{Deformation electron density}

The residual electron-density map of C-102 in the chromen2-one plane obtained after multipolar refinement against the experimental data is shown in Fig. 4. The absence of significant electron-density peaks on the covalent bonds and on atom sites testifies to the high quality of diffraction data on one hand, and on the other hand the efficiency of the Hansen \& Coppens multipolar modelling in the description of the experimental electron-density distribution.

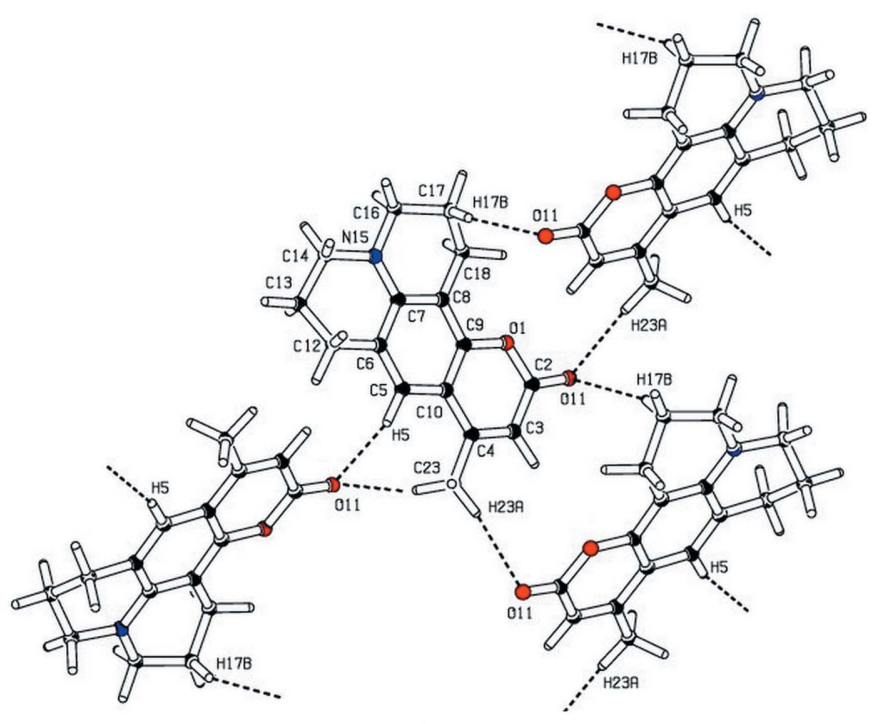

(a)

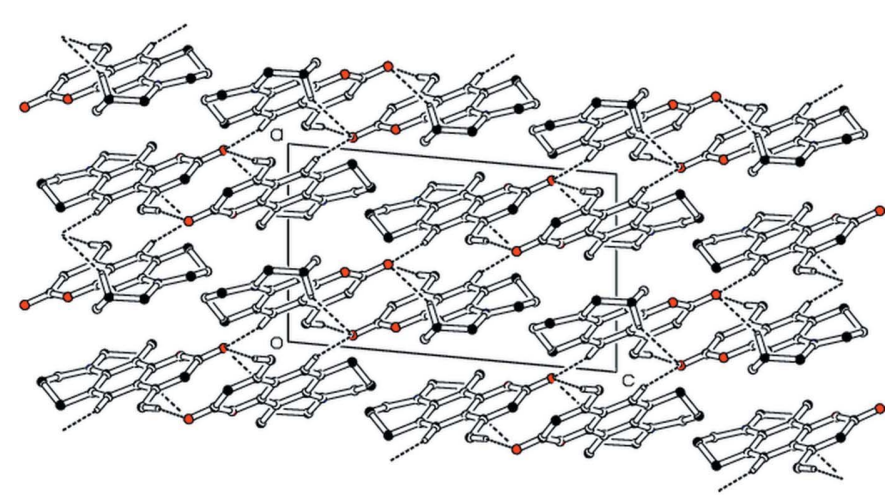

(b)

Figure 3

(a) View of the crystal packing part of C-102 showing the hydrogen bonds (dashed lines) between one molecule and its neighbours. (b) Crystal packing viewed down the $\mathbf{b}$ axis, showing molecular chains. $\mathrm{H}$ atoms not involved in hydrogen bonds have been omitted for clarity. The views were made using PLATON (Spek, 2003). 
The static deformation electron-density maps of EXPML and ELMAM2 models as well as their difference in the chromen-2-one plane are illustrated in Fig. 5. A coherent trend in the description of the deformation electron density emerges from the maps of both models (Figs. $5 a$ and $b$ ). The difference between the two maps is shown in Fig. 5(c) and confirms the good qualitative and quantitative agreement between the EXPML and ELMAM2 models.

As shown in Figs. 5(a) and (b), the covalent bonds as well as the electron lone pairs are well represented by the electrondensity peaks. On these maps, the polar character of $\mathrm{C}-\mathrm{O}$ and $\mathrm{C}-\mathrm{N}$ bonds is clearly revealed by the shift of the electrondensity towards $\mathrm{O}$ and $\mathrm{N}$ atoms, which are more electronegative. A clear difference is also visible between $\mathrm{C}-\mathrm{O}$ single and $\mathrm{C}=\mathrm{O}$ double bonds, characterized by a great disparity in electron-density peak heights, with $\sim 0.35$ and $\sim 0.85$ e $\AA^{-3}$, respectively.

The chromen-2-one ring system presents bonding electron density on the $\mathrm{C}_{\text {arom }}-\mathrm{C}_{\text {arom }}$ non-polar covalent bonds that are of almost identical shapes, with EXPML peak-height values ranging between 0.50 and 0.75 e $\AA^{-3}$. The lowest and highest electron-density peak values correspond to $\mathrm{C} 4-\mathrm{C} 10$ and $\mathrm{C} 4-$ $\mathrm{C} 3$, which are vicinal bonds of the pyran-2-one part of the molecule, where the $\mathrm{C} 4$ atom holds the methyl substituent. This difference in peak height is very likely due to the presence of the electron-donor methyl group at the 4-position in the chromen-2-one ring system. However, the average peak height of the bonding electron density in the chromen-2-one ring system is close to 0.65 e $\AA^{-3}$, a value comparable to those usually found in phenyl rings (Kubicki et al., 2002).

In both piperidine rings, electron-density peaks of all $\mathrm{C}-\mathrm{C}$ bonds have quasi-identical magnitudes $\left(0.43 \pm 0.06 \mathrm{e} \AA^{-3}\right)$, whereas a clear difference can be observed for the $\mathrm{C}-\mathrm{N}$ bonds. Indeed, two categories of $\mathrm{C}-\mathrm{N}$ bonds appear. On one hand, the $\mathrm{C} 14-\mathrm{N} 15$ and $\mathrm{C} 16-\mathrm{N} 15$ bonds with bonding

$$
1 \AA
$$

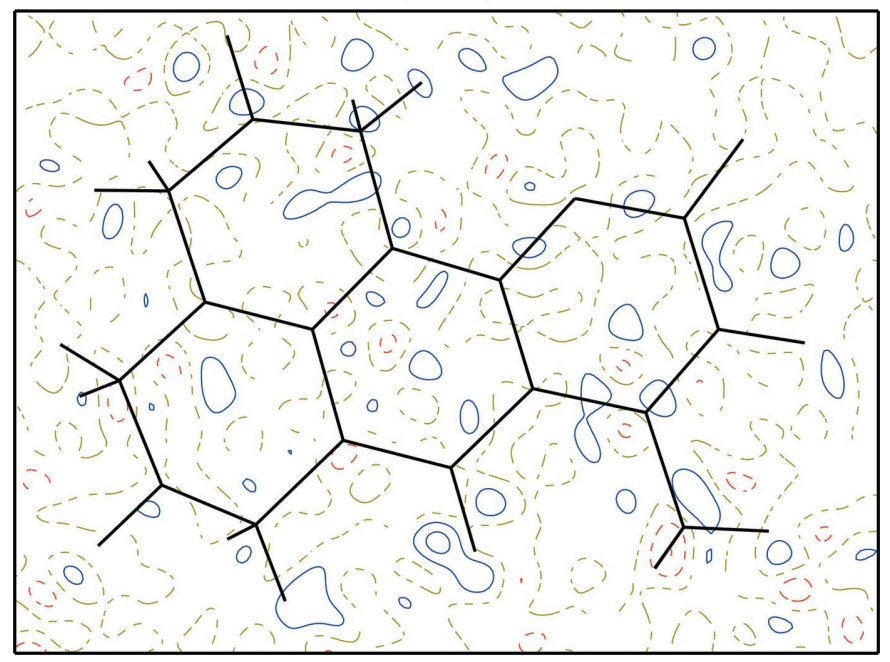

Figure 4

Residual Fourier electron-density map of the C-102 dye in the chromen-

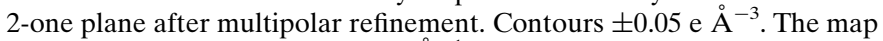
was computed up to $\sin \theta / \lambda=0.8 \AA^{-1}$. electron density reaching 0.35 and $0.4 \mathrm{e} \AA^{-3}$, respectively. On the other hand, the $\mathrm{C} 7-\mathrm{N} 15$ bond displays a significantly higher bonding electron-density peak of $0.5 \mathrm{e} \AA^{-3}$. These features are correlated to the corresponding covalent bond

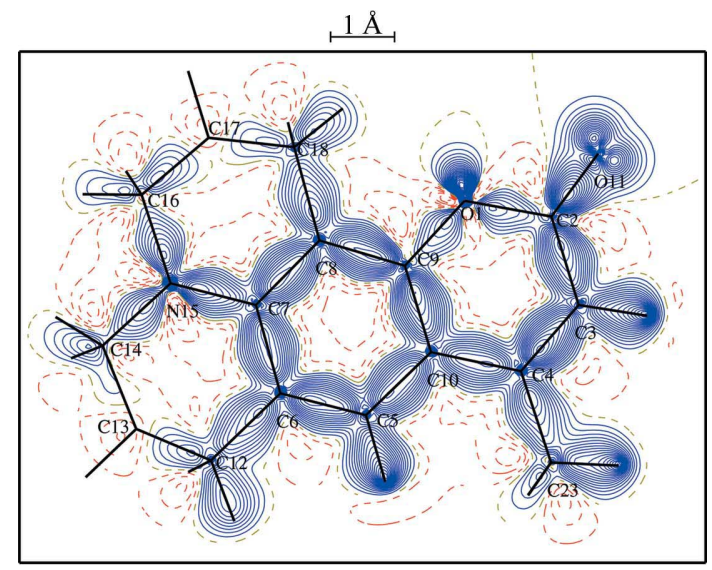

(a)

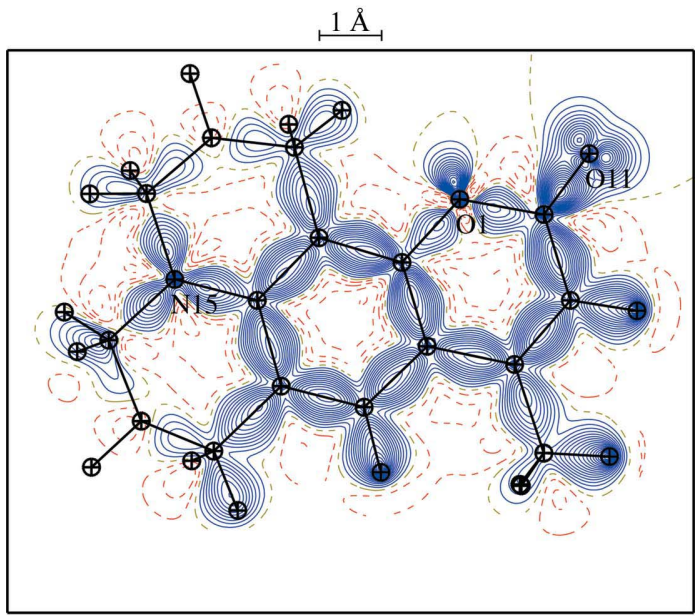

(b)

$1 \AA$

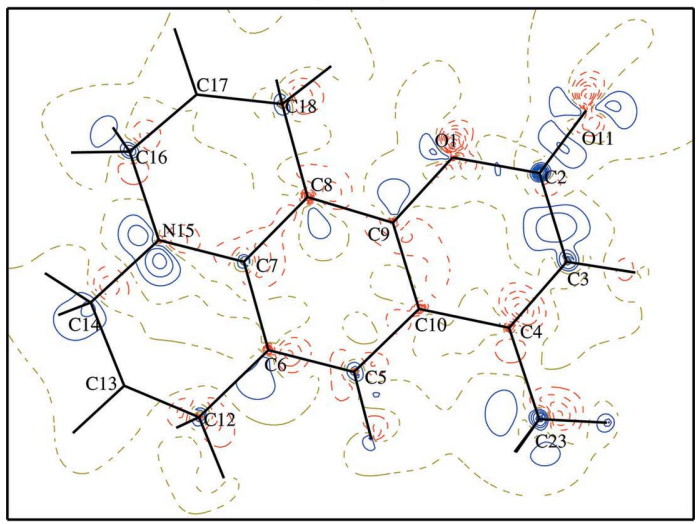

(c)

Figure 5

Static deformation electron-density maps in the chromen-2-one plane. (a) Experimental; (b) ELMAM2 transfer; $(c)$ difference ELMAM2 -

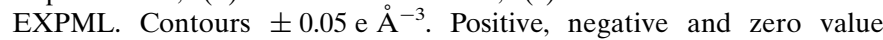
contours are in blue, red and yellow lines, respectively. In $(a)$ and $(b)$ the atom labels have been omitted for clarity. 
lengths (Table $2 a$ ). Among the three $\mathrm{C}-\mathrm{N}$ bonds, the $\mathrm{C} 7-$ $\mathrm{N} 15$ bond in which the N15 amino atom is bound to the aromatic ring, has a higher deformation electron density peak

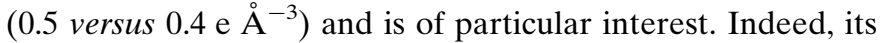
electron-density peak height is close to the values observed on the $\mathrm{C}-\mathrm{C}$ aromatic bonds, which indicates that the $\mathrm{C} 7-\mathrm{N} 15$ bond appears to have partially a double character and suggests the existence of a resonance phenomenon between the amino N15 atom and the chromen-2-one moiety.

\subsection{Topology of covalent bonds}

The topological analysis of the total electron density $\rho(r)$ and the localization of the critical points (CPs) were performed using VMoPro. The topological properties at CPs of all covalent bonds were calculated for both EXPML and ELMAM2 models (Fig. 6, Table S1). All these bonds are characterized by $(3,-1)$ critical points each having a negative value for the electron density Laplacian (Fig. 7). Furthermore, the topological values at the bond CPs in C-102 for EXPML and ELMAM2 models present the same trend and highlight an excellent quantitative agreement. The Laplacian map derived from the ELMAM2 models and the difference ELMAM2-EXPML are shown as supplementary material. Differences are difficult to see in the Laplacian maps, while a table of topological values (Table S1) enables quantitative comparison. The difference in Laplacian maps, on the other hand, gives similar information to the electron-density difference (Fig. 5c).

The two models provide generally comparable estimates of the topological properties of the charge density (Table S1). The largest differences in $\rho_{\mathrm{cp}}$ values between the two models

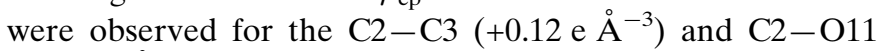
$\left(+0.09 \mathrm{e} \AA^{-3}\right)$ bonds. The root mean-square difference r.m.s.d. $\left(\rho_{\mathrm{cp}}\right)$ is 0.040 e $\AA^{-3}$, corresponding to $2.0 \%$ in relative value. For the Laplacian $\nabla^{2} \rho_{\mathrm{cp}}$, the largest discrepancies occur for the

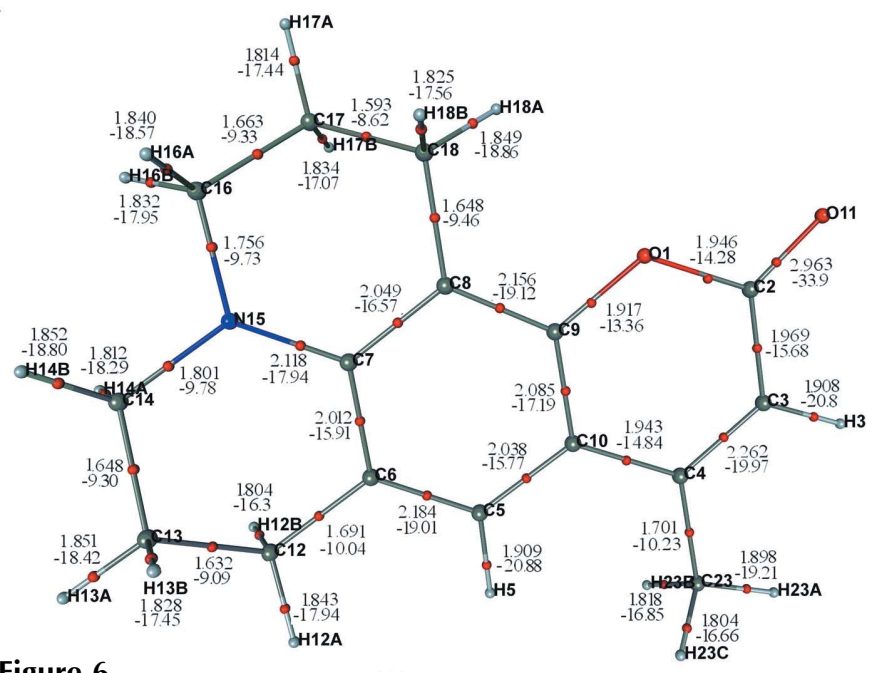

Figure 6

Topological properties at the bond critical points of C-102 for the EXPML model. The total electron density $\rho_{\text {cp }}\left(\mathrm{e}^{-3}\right)$ and its Laplacian value $\nabla^{2} \rho_{\text {cp }}\left(\mathrm{e} \AA^{-5}\right)$ are depicted near each bond CP. The ellipticities and ELMAM2 topological values are in the supplementary materials.
$\mathrm{C} 2-\mathrm{O} 1$ and $\mathrm{C} 2-\mathrm{C} 3$ bonds $\left(-2.7 \mathrm{e} \AA^{-5}\right)$ and the r.m.s.d. is 0.9 e $\AA^{-5}$ or $5.5 \%$ in relative value.

The ellipticities $\varepsilon$ at the covalent bond CPs are represented for both models in Fig. 8. The ellipticity differences do not exceed 0.07 and the r.m.s.d. is 0.026 , which corresponds to a relative difference of $20 \%$. The $\mathrm{C}_{\text {arom }}-\mathrm{C}_{\text {arom }}$ bonds of the chromen-2-one part show a cluster of $\varepsilon$ values around $0.24 \pm 0.03$ for both models and include the $\mathrm{N} 15-\mathrm{C} 7$ bond. The other two $\mathrm{C}-\mathrm{N}$ bonds, the $\mathrm{C}-\mathrm{O}$ and $\mathrm{C}_{\text {arom }}-\mathrm{Csp} p^{3}$ bonds show moderate ellipticities around $0.12 \pm 0.02$, while the $\mathrm{Cs} p^{3}-\mathrm{Csp}^{3}$ bonds all have ellipticities lower than 0.04 .

According to the Laplacian map (Fig. 7), the asymmetric bonds $(\mathrm{C}-\mathrm{O}$ and $\mathrm{C}-\mathrm{N})$ show larger regions of electron accumulation on the bonds on the side of the heaviest atom. In these heteronuclear bonds, the CPs also lie significantly closer to the $\mathrm{C}$ atom; this is due to a greater accumulation of the electron density towards the more electronegative $\mathrm{O}$ and $\mathrm{N}$ atoms. The topological features such as the electron density magnitude and the Laplacian values at the CPs correlate in an excellent way to the structural features and to the peak heights of electron density. Again, they reveal the very pronounced difference between the single and double bonds occurring in the structure. For example, the $\mathrm{C}-\mathrm{O}$ bond type illustrates this feature well. The electron density and Laplacian values at the

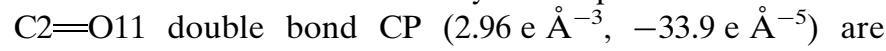
significantly larger than the values observed for the single

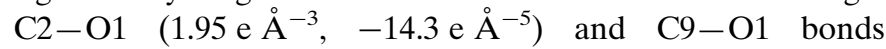
(1.92 e $\AA^{-3},-13.4$ e $\left.\AA^{-5}\right)$. The ELMAM2 electron density yields topological values for the $\mathrm{C}-\mathrm{O}$ bonds very similar to the EXPLM model.
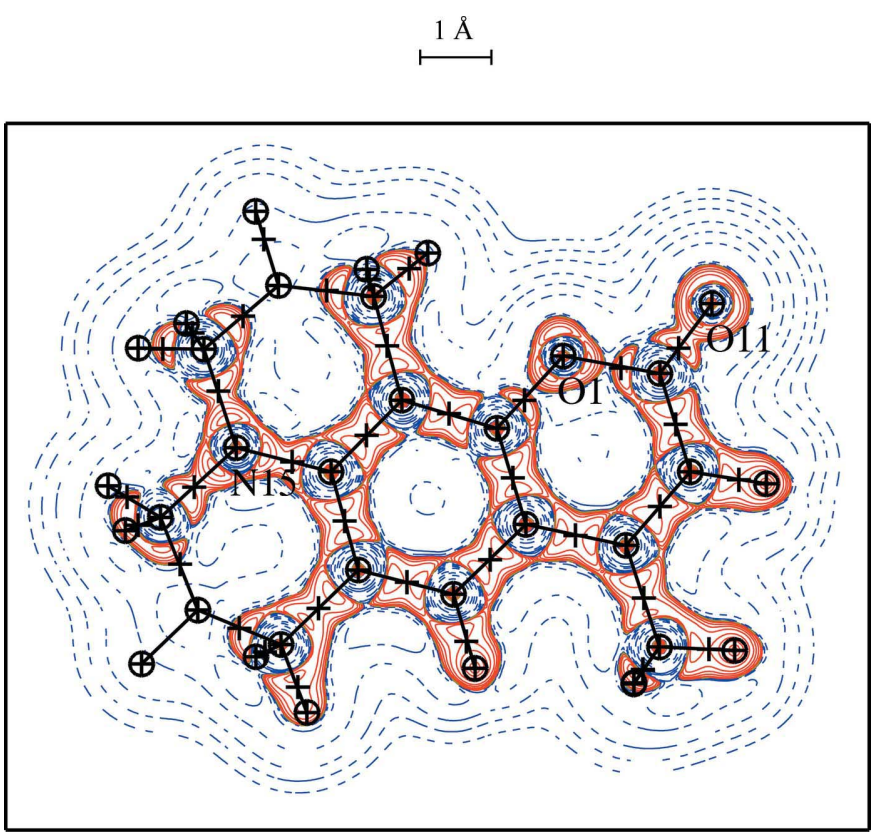

Figure 7

Laplacian of the total experimental electron density in a chromen-2-one ring system plane. Contours $\pm 2,4,8 \times 10^{n} \mathrm{e}^{-5}, n=-1,0,1$. Blue contours indicate the positive region; red lines - negative regions; yellow dashed line - zero regions. Bond critical points are denoted with + symbols. 
Table 4

Topological properties at the critical points of $\mathrm{H} \cdots \mathrm{O}$ and $\mathrm{H} \cdots \mathrm{N}$ intermolecular interactions in the crystal packing of C-102 for the EXPML (first entry) and ELMAM2 (second entry in italics) models.

$d_{A 1-A 2}, d_{A 1-\mathrm{CP}}$ and $d_{\mathrm{CP}-A 2}$ are the distances $(\AA)$ between the two atoms, between the first atom and the $\mathrm{CP}$, and between the $\mathrm{CP}$ and the second atom. $\rho_{\mathrm{cp}}$ is the total electron density $\left(\mathrm{e} \AA^{-3}\right)$ at the CP and $\nabla^{2} \rho_{\mathrm{cp}}$ its Laplacian $\left(\mathrm{e} \AA^{-5}\right) \cdot \lambda_{3}, \lambda_{2}, \lambda_{1}$ are the eigenvalues $\left(\mathrm{e} \AA^{-5}\right)$ of the Hessian matrix $\partial^{2} \rho / \partial x_{i} \partial x_{j}$. $\varepsilon=\lambda_{1} / \lambda_{2}-1$ is the ellipticity. The r.m.s. values of the topological properties are also shown. For each topological criterion, the discrepancy between values $v 1$ and $v 2$ issued from EXPML and ELMAM2 models respectively is defined as r.m.s. $(v 1-v 2) /$ r.m.s. $(v 1)$

\begin{tabular}{|c|c|c|c|c|c|c|c|c|c|}
\hline$X \cdots \mathrm{H}$ & $d_{A 1-A 2}(\AA)$ & $d_{A 1-\mathrm{CP}}(\AA)$ & $d_{\mathrm{CP}-A 2}(\AA)$ & $\rho_{\text {cp }}\left(\mathrm{e} \AA^{-3}\right)$ & $\nabla^{2} \rho_{\text {cp }}\left(\mathrm{e} \AA^{-3}\right)$ & $\lambda_{1}\left(\mathrm{e} \AA^{-5}\right)$ & 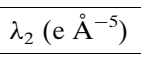 & $\lambda_{3}\left(\mathrm{e} \stackrel{\AA}{\mathrm{A}}-^{5}\right)$ & $\varepsilon$ \\
\hline \multirow[t]{2}{*}{$\mathrm{O} 11 \cdots \mathrm{H} 5^{\mathrm{i}}$} & 2.3773 & 1.4007 & 0.9781 & 0.0715 & 0.76 & -0.30 & -0.28 & 1.34 & 0.07 \\
\hline & 2.3720 & 1.4082 & 0.9643 & 0.0691 & 0.86 & -0.29 & -0.28 & 1.43 & 0.04 \\
\hline $\mathrm{O} 11 \cdots \mathrm{H} 17 B^{\mathrm{ii}}$ & 2.4767 & 1.4568 & 1.0222 & 0.0534 & 0.78 & -0.18 & -0.17 & 1.13 & 0.06 \\
\hline \multirow[t]{2}{*}{$\mathrm{O} 11 \cdots \mathrm{H} 23 A^{\mathrm{iii}}$} & 2.5479 & 1.4551 & 1.0936 & 0.0562 & 0.64 & -0.20 & -0.20 & 1.05 & 0.0 \\
\hline & 2.5415 & 1.4796 & 1.0627 & 0.0516 & 0.61 & -0.20 & -0.19 & 1.00 & 0.05 \\
\hline \multirow[t]{2}{*}{$\mathrm{O} 11 \cdots \mathrm{H} 12 A^{\mathrm{i}}$} & 2.9053 & 1.6736 & 1.2656 & 0.0274 & 0.33 & -0.05 & -0.04 & 0.42 & 0.25 \\
\hline & 2.8880 & 1.6740 & 1.2496 & 0.0262 & 0.33 & -0.06 & -0.05 & 0.43 & 0.2 \\
\hline \multirow[t]{2}{*}{$\mathrm{O} 11 \cdots \mathrm{H} 14 B^{\mathrm{iv}}$} & 2.7730 & 1.6064 & 1.1751 & 0.0333 & 0.51 & -0.08 & -0.05 & 0.65 & 0.6 \\
\hline & 2.7589 & 1.6169 & 1.1507 & 0.0327 & 0.53 & -0.09 & -0.06 & 0.69 & 0.5 \\
\hline \multirow[t]{2}{*}{$\mathrm{O} 1 \cdots \mathrm{H} 3^{\mathrm{iii}}$} & 2.7843 & 1.5771 & 1.2125 & 0.0351 & 0.37 & -0.11 & -0.10 & 0.59 & 0.1 \\
\hline & 2.7856 & 1.6132 & 1.1765 & 0.0305 & 0.37 & -0.10 & -0.09 & 0.55 & 0.11 \\
\hline \multirow[t]{2}{*}{$\mathrm{N} 15 \cdots \mathrm{H} 23 B^{\mathrm{v}}$} & 2.7414 & 1.6092 & 1.1423 & 0.0464 & 0.54 & -0.12 & -0.09 & 0.75 & 0.33 \\
\hline & 2.7448 & 1.6270 & 1.1243 & 0.0411 & 0.51 & -0.10 & -0.10 & 0.71 & 0.0 \\
\hline r.m.s.(EXPML) & & & & 0.047 & 0.58 & 0.16 & 0.15 & 0.88 & 0.28 \\
\hline
\end{tabular}

The symmetry codes are: (i) $x-\frac{1}{2},-y+\frac{3}{2}, z-\frac{1}{2}$; (ii) $-x+\frac{3}{2}, y+\frac{1}{2},-z-\frac{1}{2}$; (iii) $-x+\frac{3}{2}, y-\frac{1}{2},-z-\frac{1}{2}$; (iv) $-x+1,-y+1,-z$; (v) $-x+2,-y+1,-z$.

The $\mathrm{C}-\mathrm{C}$ bonds in the chromen-2-one moiety show topological properties at CPs similar to those of the phenyl ring (Kubicki et al., 2002; Bouhmaida et al., 2009) and are comparable to those observed by Howard et al. (2009) in the study of the experimental charge density of coumarin-3carboxylic acid. As expected, the values of these topological parameters clearly indicate a significant $\pi$ character common to all $\mathrm{C}-\mathrm{C}$ bonds of the chromen-2-one ring system.

The influence of the methyl group substituted at position 4 in the chromen-2-one ring is also shown by the magnitude of the topological parameters $\rho$ and $\nabla^{2} \rho$ at the CPs, which are higher for the $\mathrm{C} 3-\mathrm{C} 4$ bond than for the $\mathrm{C} 4-\mathrm{C} 10$ bond (Fig. $6)$. The presence of the electron-donor methyl group facilitates the electron populating toward the $\mathrm{C} 3-\mathrm{C} 4$ bond, which is closer to the $\mathrm{C} 2=\mathrm{O} 11$ carbonyl group rather than to the $\mathrm{C} 4-\mathrm{C} 10$ bond direction.

The topological analysis of the $\mathrm{C}-\mathrm{N}$ bond indeed confirms the existence of two categories of $\mathrm{C}-\mathrm{N}$ bonds in this laser dye molecule. The values of the charge density and Laplacian at the $\mathrm{C} 7-\mathrm{N} 15 \mathrm{CP}\left(\rho=2.12 \mathrm{e} \AA^{-3}, \nabla^{2} \rho=-17.9 \mathrm{e}^{-5}\right)$ are similar to those of the $\mathrm{C}-\mathrm{C}$ bonds of the chromen-2-one moiety. The two other $\mathrm{C}-\mathrm{N}$ bonds show significantly smaller values: $\mathrm{C} 14-\mathrm{N} 15\left(\rho=1.80 \mathrm{e} \AA^{-3}, \nabla^{2} \rho=-9.78 \AA^{-5}\right)$ and $\mathrm{C} 16-\mathrm{N} 15\left(\rho=1.76\right.$ e $\left.\AA^{-3}, \nabla^{2} \rho=-9.73 \mathrm{e}^{-5}\right)$.

These values indicate a higher electron concentration at the critical point of the $\mathrm{C} 7-\mathrm{N} 15$ bond compared with those of the C14-N15 and $\mathrm{C} 16-\mathrm{N} 15$ bonds. Furthermore, the ellipticity values at these same critical points $(0.20$ versus 0.14 and 0.10$)$ also confirm the greater $\pi$ character of the $\mathrm{C} 7-\mathrm{N} 15$ bond. As already observed in the electron-density peak-height analysis, these features reveal that the $\mathrm{C} 7-\mathrm{N} 15$ bond presents a double-bond character compared with the $\mathrm{C} 14-\mathrm{N} 15$ and
$\mathrm{C} 16-\mathrm{N} 15$ bonds. The similarity observed at the level of the topological properties of the $\mathrm{C}-\mathrm{C}$ bonds in the chromen-2one system ring and of the $\mathrm{C} 7-\mathrm{N} 15$ bond suggests the existence of electron-density resonance and consequently the $\pi$ electron cloud delocalization in this part of the molecule.

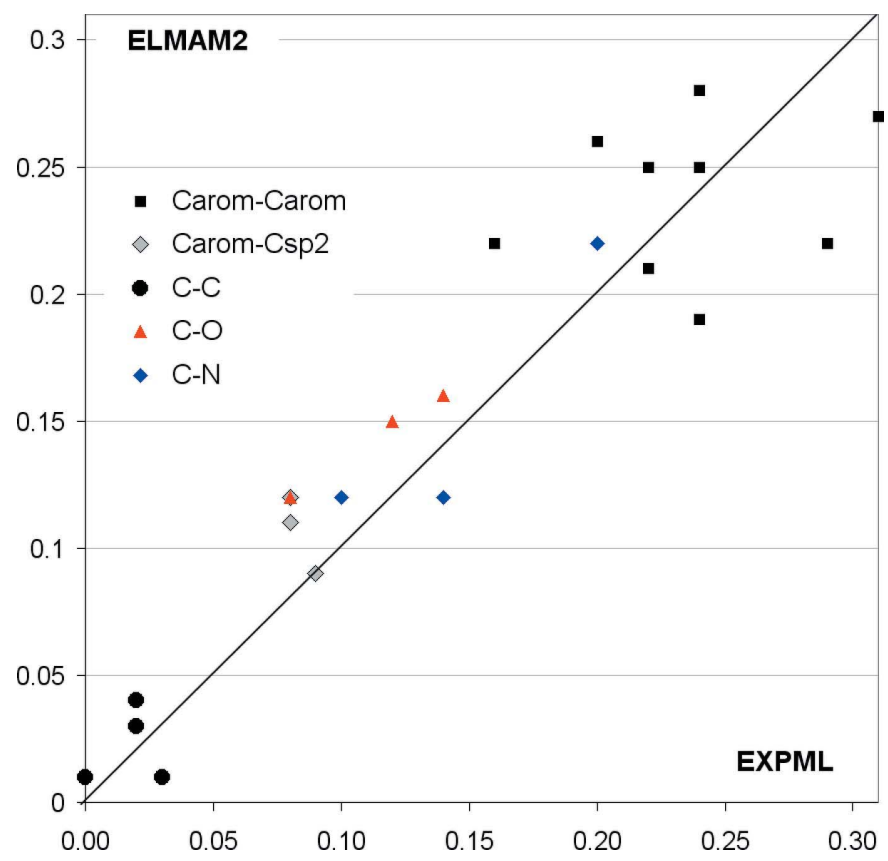

Figure 8

Scatterplot representing the ellipticity values at covalent bond CPs obtained from the EXPML versus ELMAM2 model. 
Table 5

Atomic net charges (e), defined from the Hansen \& Coppens (1978) model, as $N_{\text {val }}-P_{\text {val }}$, of the $\mathrm{C}, \mathrm{N}$ and $\mathrm{O}$ atoms in C-102 for the EXPML and ELMAM2 models.

\begin{tabular}{lcc}
\hline Atoms & EXPML & ELMAM2 \\
\hline O1 & $-0.22(2)$ & -0.25 \\
O11 & $-0.22(3)$ & -0.14 \\
N15 & $-0.23(3)$ & -0.22 \\
C2 & $+0.08(4)$ & -0.17 \\
C3 & $+0.10(5)$ & -0.06 \\
C4 & $-0.08(4)$ & -0.05 \\
C5 & $+0.08(5)$ & -0.06 \\
C6 & $-0.10(4)$ & -0.05 \\
C7 & $+0.09(4)$ & -0.00 \\
C8 & $-0.08(4)$ & +0.05 \\
C9 & $+0.06(4)$ & +0.05 \\
C10 & $-0.04(4)$ & +0.05 \\
C12 & $+0.09(4)$ & -0.01 \\
C13 & $+0.05(4)$ & -0.01 \\
C14 & $+0.31(6)$ & +0.13 \\
C16 & $+0.29(6)$ & +0.13 \\
C17 & $+0.05(4)$ & -0.01 \\
C18 & $+0.09(4)$ & -0.01 \\
C23 & $+0.20(10)$ & -0.03 \\
\hline
\end{tabular}

\subsection{Topology of $\mathbf{C}-\mathbf{H} \cdots X$ interactions}

The nature of the Hirshfeld surface contacts in the crystal packing were computed by the program CrystalExplorer (McKinnon et al., 2004). H. .H account for $56 \%$ of the crystalpacking contacts, while $\mathrm{C} \cdot \mathrm{H}$ and $\mathrm{O} \cdots \mathrm{H}$ account for $20 \%$. The intermolecular interactions were analyzed on the basis of the atoms in molecules (AIM) theory (Bader, 1990). The experimental and ELMAM2 topological parameters at the CPs are summarized in Table 4. As expected, the two $\mathrm{O}$ atoms which are possible hydrogen-bonds acceptors are involved in $\mathrm{C}-\mathrm{H} \cdots \mathrm{O}$ intermolecular interactions. The $\mathrm{N}$ atom is slightly pyramidal and forms a weak $\mathrm{C}-\mathrm{H} \cdots \mathrm{N}$ interaction with $\mathrm{H} 23 B$.

The intermolecular interactions network is particularly dense around the carbonyl O11 atom, which is the strongest potential hydrogen acceptor site on the molecule. Indeed, among the eight $(3,-1)$ CPs found along the $\mathrm{C}-\mathrm{H} \cdots X$ interaction paths (Table 4), the $\mathrm{O} 11$ atom is involved in six of them, while the atoms $\mathrm{O} 1$ and $\mathrm{N} 15$ are involved in the two remaining ones.

All these CPs have positive Laplacian values, characteristics of closed-shell interactions and display an average electrondensity magnitude of 0.04 (1) e $\AA^{-3}$. The electron density, Laplacian, Hessian eigenvalues and ellipticities on these intermolecular CPs show very similar r.m.s. values in the EXPML and ELMAM2 models. The discrepancy between the two models is low, between 5 and $9 \%$, for the different properties, except for the ellipticity which is a quotient and is very sensitive to variations of small numbers.

The first three interactions to $\mathrm{O} 11$ in Table 4 have $\mathrm{H}$... O distances lower than the sum of the van der Waals radii and

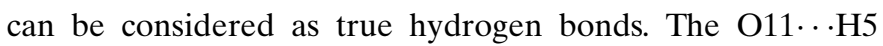
hydrogen bond is the strongest, as indicated by the large $\lambda_{3}$ eigenvalue and electron-density value at the $\mathrm{CP}$ of the interaction path (Espinosa et al., 1999).
The classic role devolved to these $\mathrm{H} \cdots \mathrm{O}$ and $\mathrm{H} \cdots \mathrm{N}$ interactions is the strengthening of the crystal packing cohesion. They also lead to the formation of optimal supramolecular architecture, in which the $\mathrm{O} 11$ atom site plays the leading role as an acceptor agent in the process of intermolecular charge attraction within the crystal.

\subsection{Electrostatic potential and net atomic charges}

The electrostatic potential generated by the C-102 molecule dye extracted from the crystal has been calculated from the electron-density distribution of the EXPML and ELMAM2 models. The net atomic charges have also been calculated and are reported in Table 5. Examination of Figs. $9(a)$ and $(b)$ shows that the shapes of the molecular electrostatic potential are globally similar, which shows the good qualitative and quantitative agreement between the EXPML and ELMAM2 models.

The unique region of the molecule presenting a negative electrostatic potential in Figs. $9(a)$ and $(b)$ is in the pyran-2one part of the molecule and covers, as expected, the $\mathrm{O} 11$ and $\mathrm{O} 1$ atom sites. This negative electrostatic potential reaches its minimum value near the O11 carbonyl atom electron lone

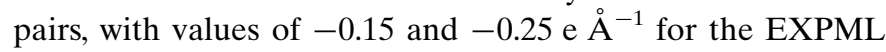
and ELMAM2 models. This observation is supported by the magnitudes of the net atomic charges $N_{\text {val }}-P_{\text {val }}$ of O11 and O1 atoms, which are both -0.22 (3) e for the EXPML model, -0.14 and -0.25 e, respectively, for the ELMAM2 model.

The N15 atom has a negative net charge comparable to that of the $\mathrm{O} 1$ atom in both models, which is in disagreement with the results suggested by the studies of 7-aminocounarin dyes in the liquid phase (Nad et al., 2003; Senthilkumar et al., 2004; Barik et al., 2005), where the $\mathrm{N}$ atom is positively charged in the ICT structure (Scheme 2).

The negative character of the charge carried by the amino $\mathrm{N} 15$ atom in the crystalline environment can be explained in the following way. The N15 atom participates in the formation of the ICT structure by means of its electron lone pair which is in resonance with the chromen-2-one system $\pi$-cloud during the process of intramolecular charge transfer. The N15 atom is slightly pyramidal and also functions as a proton acceptor site in intermolecular charge-transfer, which is illustrated by the $\mathrm{C} 23-\mathrm{H} 23 B \cdots \mathrm{N} 15\left(d_{\mathrm{HN}}=2.74 \AA\right)$ interaction, whose topological characteristics at the $\mathrm{CP}$ are reported in Table 4. A recent report on the molecular characterization of C-102 using a sophisticated method of calculation (hybrid meta-GGA M05-2X functional within the framework of the DFT theory; Glossman-Mitnik, 2009) shows the existence of a negative charge on the N15 atom. Furthermore, quantum mechanics calculations on the basis of empirical methods on a similar molecule also indicate the presence of a negative charge on the N atom (Kumar \& Maroncelli, 1995; Diraison et al., 1998).

The electropositive potential surfaces (Figs. $10 a$ and $b$ ) extend around the $\mathrm{H}$ atoms and correlate in an excellent way to the positive charges of the $\mathrm{H}$ atoms bound to $\mathrm{C}$ atoms.

The molecular electrostatic potential maps (Fig. 9) and surfaces (Fig. 10) of both models show well a dissymmetric 
distribution of charges along the molecule of C-102. This asymmetric charge distribution induces high polarization effects along the molecule which is attested by significant molecular dipolar moment values (Table 6).

\subsection{Molecular dipole moments}

It is well known that the molecular dipole moment is an observation of fundamental importance in charge-transfer phenomenon within a molecular entity. The quantitative charge-density analysis of accurate single-crystal X-ray diffraction data provide detailed information on the dipole moment of molecules in a crystalline environment. However, the molecular dipole moments derived from such studies often

$1 \AA$

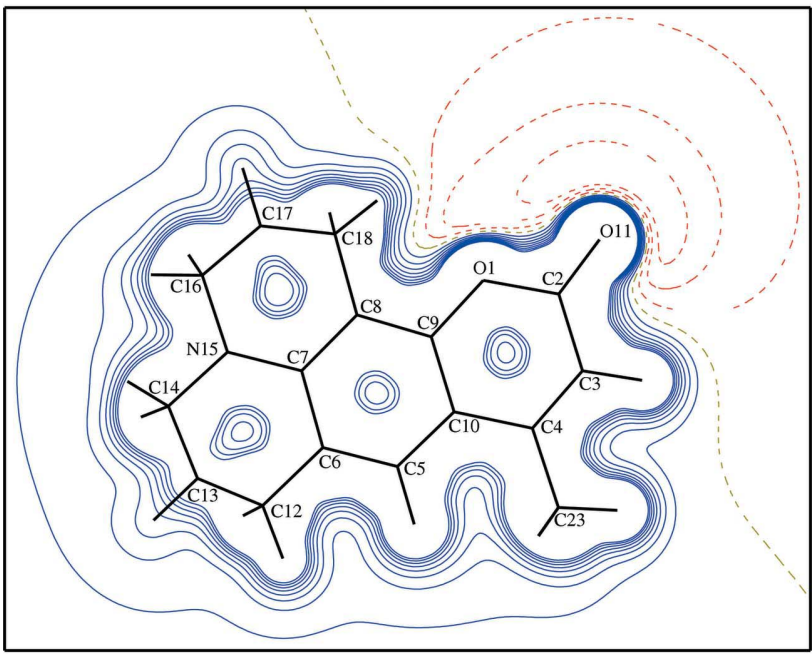

(a)

$1 \AA$

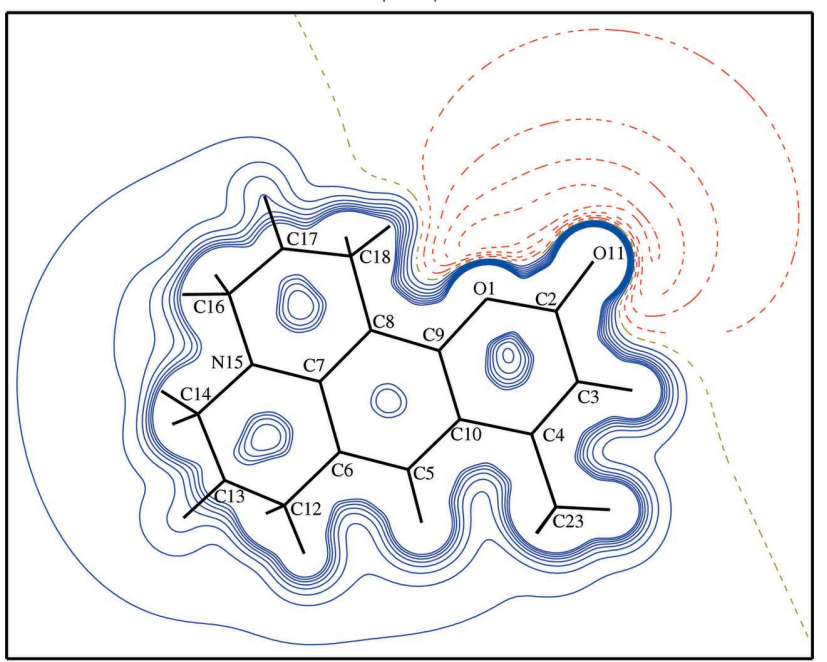

(b)

Figure 9

Molecular electrostatic potential maps around the chromen-2-one plane generated by a C-102 molecule isolated from the crystal. (a) Experimental multipolar refinement; $(b)$ ELMAM2 transferred multipole

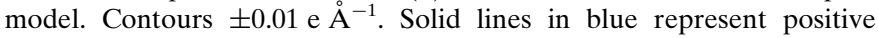
contours; dashed lines in red - negative contours; yellow dashed lines zero contours.
Table 6

Molecular dipole moments (Debye) in C-102 for EXPML and ELMAM2 models and their enhancements compared with two other independent estimates.

The theo gas value is obtained using DFT calculations using the PBEO functional (see text). The enhancement is defined by $\Delta \mu / \mu=\left(\mu-\mu_{\text {theo_gas }}\right) /$ $\mu_{\text {theo_gas. }}$

\begin{tabular}{lll}
\hline & $\mu$ & $\Delta \mu / \mu(\%)$ \\
\hline Theo gas & 5.99 & - \\
Solution & 6.98 & +16 \\
EXPLM & 9.43 & +57 \\
ELMAM2 & 13.80 & +130 \\
\hline
\end{tabular}

present pronounced enhancements compared with independent theoretical estimates in which intermolecular effects are not taken into account (Spackman et al., 2007).

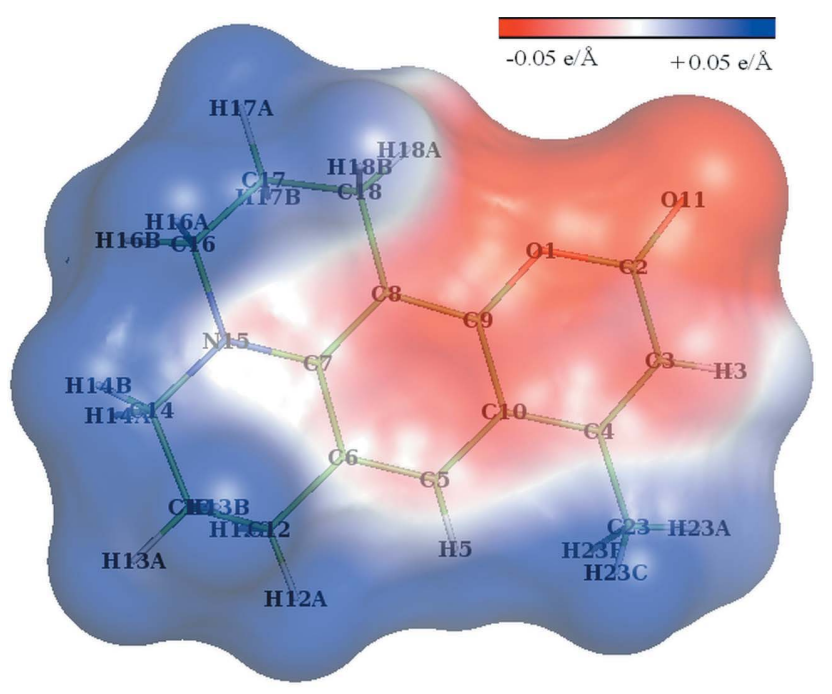

(a)

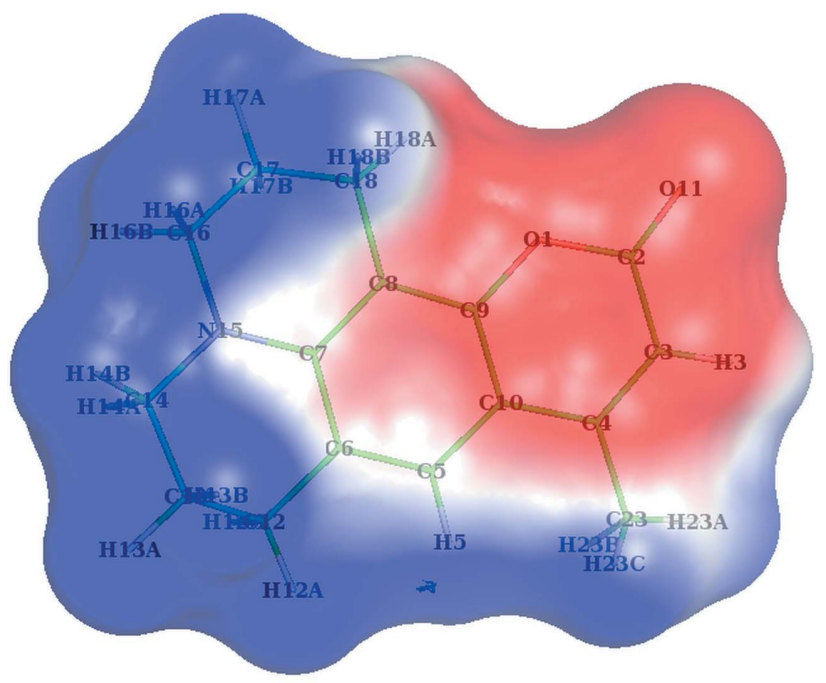

(b)

Figure 10

Electrostatic potential at the van der Waals molecular surface $(a)$ from experimental charge density; $(b)$ from the ELMAM2 database transferred model. 
Table 7

AIM charges according to the Bader definition and derived from electric field flux (e) in coumarin.

Moduli of total atomic forces $\left(\mathrm{e}^{2} \AA^{-2}\right)$ are given in the last two columns. Results are listed for C-102 from both EXPML and ELMAM2 multipolar parameters for comparison.

\begin{tabular}{|c|c|c|c|c|c|c|}
\hline \multirow[b]{2}{*}{ Atom } & \multicolumn{2}{|c|}{ Bader charges } & \multicolumn{2}{|c|}{$E$-flux charges } & \multicolumn{2}{|c|}{ Total atom forces } \\
\hline & EXPML & ELMAM2 & EXPML & ELMAM2 & EXPML & ELMAM2 \\
\hline O1 & -0.93 & -1.01 & -1.01 & -0.90 & 0.53 & 0.50 \\
\hline O11 & -1.11 & -1.29 & -1.10 & -1.13 & 1.59 & 2.22 \\
\hline $\mathrm{C} 2$ & 1.23 & 1.37 & 1.25 & 1.20 & 0.91 & 1.38 \\
\hline $\mathrm{C} 7$ & 0.40 & 0.29 & 0.37 & 0.30 & 0.29 & 0.22 \\
\hline $\mathrm{C} 9$ & 0.40 & 0.42 & 0.43 & 0.33 & 0.35 & 0.36 \\
\hline $\mathrm{C} 14$ & 0.26 & 0.19 & 0.22 & 0.02 & 0.17 & 0.24 \\
\hline C16 & 0.28 & 0.17 & 0.25 & 0.02 & 0.25 & 0.22 \\
\hline $\mathrm{C} 3$ & 0.02 & -0.18 & 0.07 & -0.10 & 0.09 & 0.09 \\
\hline $\mathrm{C} 4$ & -0.07 & -0.03 & -0.05 & -0.01 & 0.07 & 0.17 \\
\hline C5 & 0.01 & -0.12 & -0.07 & -0.15 & 0.06 & 0.03 \\
\hline C6 & -0.06 & -0.01 & -0.03 & -0.06 & 0.09 & 0.16 \\
\hline $\mathrm{C} 8$ & -0.12 & -0.06 & -0.10 & -0.13 & 0.13 & 0.18 \\
\hline $\mathrm{C} 10$ & -0.06 & 0.03 & -0.03 & -0.06 & 0.06 & 0.06 \\
\hline $\mathrm{C} 12$ & -0.08 & -0.09 & -0.09 & -0.21 & 0.16 & 0.14 \\
\hline C13 & -0.04 & -0.05 & -0.10 & -0.21 & 0.14 & 0.14 \\
\hline C17 & -0.02 & -0.01 & -0.09 & -0.16 & 0.15 & 0.16 \\
\hline C18 & -0.04 & -0.01 & -0.07 & -0.15 & 0.12 & 0.15 \\
\hline $\mathrm{C} 23$ & -0.06 & -0.14 & -0.06 & -0.27 & 0.17 & 0.20 \\
\hline N15 & -0.93 & -0.93 & -0.90 & -1.08 & 0.23 & 0.12 \\
\hline H3 & 0.08 & 0.14 & 0.14 & 0.19 & 0.25 & 0.26 \\
\hline H5 & 0.06 & 0.13 & 0.12 & 0.18 & 0.21 & 0.26 \\
\hline $\mathrm{H} 12 A$ & 0.05 & 0.07 & 0.09 & 0.12 & 0.23 & 0.23 \\
\hline $\mathrm{H} 12 B$ & 0.05 & 0.07 & 0.11 & 0.12 & 0.23 & 0.23 \\
\hline $\mathrm{H} 13 A$ & 0.03 & 0.06 & 0.10 & 0.12 & 0.21 & 0.24 \\
\hline $\mathrm{H} 13 B$ & 0.04 & 0.06 & 0.11 & 0.11 & 0.21 & 0.23 \\
\hline $\mathrm{H} 14 A$ & 0.00 & 0.09 & 0.06 & 0.14 & 0.21 & 0.23 \\
\hline $\mathrm{H} 14 B$ & 0.06 & 0.09 & 0.12 & 0.14 & 0.23 & 0.23 \\
\hline $\mathrm{H} 16 A$ & 0.00 & 0.10 & 0.06 & 0.14 & 0.21 & 0.23 \\
\hline $\mathrm{H} 16 B$ & 0.03 & 0.10 & 0.10 & 0.15 & 0.22 & 0.23 \\
\hline $\mathrm{H} 17 A$ & 0.02 & 0.04 & 0.07 & 0.09 & 0.21 & 0.22 \\
\hline $\mathrm{H} 17 B$ & 0.06 & 0.05 & 0.10 & 0.10 & 0.23 & 0.22 \\
\hline $\mathrm{H} 18 A$ & 0.10 & 0.05 & 0.15 & 0.11 & 0.25 & 0.24 \\
\hline H18B & 0.06 & 0.07 & 0.11 & 0.12 & 0.24 & 0.24 \\
\hline $\mathrm{H} 23 A$ & 0.07 & 0.08 & 0.12 & 0.13 & 0.31 & 0.29 \\
\hline $\mathrm{H} 23 B$ & 0.03 & 0.07 & 0.09 & 0.13 & 0.30 & 0.28 \\
\hline $\mathrm{H} 23 C$ & 0.06 & 0.07 & 0.12 & 0.13 & 0.31 & 0.28 \\
\hline
\end{tabular}

Table 6 lists the dipole moment values of C-102 obtained from the X-ray experimental and transferred multipole models and from two other approaches:

(i) from experimental measurements in chloroform solution (Muhlpfordt et al., 1999), a non-polar solvent in which there are no strong solute-solvent interactions;

(ii) from DFT calculations using the PBEO functional at the 6-311G(d,p) basis set level (Cave \& Castner, 2002), which simulates the gas-phase.

The dipole moment measured in solution is slightly higher than that computed in the gas phase. Enhancement of the magnitudes of the dipole moments derived from both experimental and ELMAM2 multipolar models with respect to the value obtained from the theoretical calculations are reported in Table 6. As expected, the molecular dipole moments in the crystal obtained from both multipolar models present substantial enhancements compared with those derived from the non-polar solution and gas phases (Spackman et al., 2007; Paul et al., 2011). The EXPML model presents a dipole moment enhancement $(+57 \%)$ which is acceptable. For Spackman et al. (2007) an increase in excess of $100 \%$ is conceivable but depends on crystal packing. The dipole moment obtained from the transferred ELMAM2 model is however significantly larger than the experimental one.

The experimental dipole moment value of C-102 in solution $(6.98 \mathrm{D})$ is of particular interest. Indeed, this value lies in the range observed for the molecules 7-aminocoumarin $\mathrm{C} 1$ and C30 (6.35 and 7.6 D in the liquid phase; Senthilkumar et al., 2004; Barik et al., 2005), in which substantial intramolecular charge transfer was observed. This suggests the existence of intramolecular charge transfer in C-102. In the crystal environment, this intramolecular charge transfer is extended to a charge transfer between molecules induced by hydrogen-bond interactions and revealed by the molecular dipole moment enhancement.

\subsection{Electrostatic field derived atomic charges and forces}

Table 7 lists the atomic charges $\left(Q_{\text {Eflux }}\right)$ and forces derived from the electrostatic field calculated from C-102 EXPML and ELMAM2 electron density. For comparison, the EXPML and ELMAM2 derived charges $\left(Q_{\text {AIM }}\right)$ obtained from integration of the electron density within atomic basis using the BADERWIN program are also listed; they show a high correlation of $98.5 \%$.

A good consistency is obtained between the two $Q_{\text {Eflux }}$ charge calculations and the EXPML $Q_{\text {AIM }}$ charges. The largest discrepancy between EXPML $Q_{\text {Eflux }}$ and $Q_{\text {AIM }}$ charges, occurring on the $\mathrm{O} 1$ atom, does not exceed $0.08 \mathrm{e}$. As expected from the atomic hybridization, the carboxyl $\mathrm{O} 11$ atom exhibits the highest negative EXPML charge $\left(Q_{\text {Eflux }}=-1.10 \mathrm{e}\right)$. The most positive charge (1.25 e) is obtained on the ester $\mathrm{C} 2$ atom. The N15 atom and the $\mathrm{O} 1$ atoms also exhibit highly negative charges $(-0.90$ and $-1.01 \mathrm{e})$. The $\mathrm{C} 14, \mathrm{C} 16$ and $\mathrm{C} 7$ atoms, which are connected to the $\mathrm{N}$ atom and $\mathrm{C} 9$ atom, which is connected to $\mathrm{O} 1$, exhibit moderate positive charges, in the +0.23 to +0.43 e range. All other $\mathrm{C}$ atoms exhibit very small charges ( -0.06 e on average for $Q_{\text {Eflux }}$ of the EXPLM model). The $\mathrm{H}$ atoms are overall slightly positively charged: the highest charges $(+0.14$ e and +0.15 e) are obtained on the $\mathrm{H} 3$ and $\mathrm{H} 18 A$ atoms.

The moduli of the atomic electrostatic forces calculated on the C-102 EXPML model are also given in Table 7. As pointed out earlier (Bouhmaida \& Ghermani, 2008), the total force, resulting from the sum of the interatomic forces, reflects the anisotropy of the electron-density distribution in different bonding directions. It is also worth noting that the atomic forces depend on the sign and the magnitude of the electrostatic field components in the interatomic regions. The atomic forces therefore depend on the hybridization state and on the chemical symmetry environment of the atomic site more than on the nature of the atom itself. For instance, atoms involved in a $\pi$ bond (polar) show electrostatic forces greater than 
Table 8

Interatomic forces $\left(\mathrm{e}^{2} \AA^{-2}\right)$ calculated from the flux of the electric field through interatomic surfaces.

Results are given for C-102 from both EXPML and ELMAM2 library for comparison.

\begin{tabular}{|c|c|c|c|c|c|}
\hline Bonded atoms & EXPML & ELMAM2 & Bonded atoms & EXPML & ELMAM2 \\
\hline Double $\mathrm{C}=\mathrm{O}$ bond & & & $\mathrm{C}-\mathrm{N}$ bonds & & \\
\hline $\mathrm{C} 2-\mathrm{O} 11$ & 1.18 & 1.79 & $\mathrm{C} 7-\mathrm{N} 15$ & 0.23 & 0.16 \\
\hline Single $\mathrm{C}-\mathrm{O}$ bonds & & & $\mathrm{C} 14-\mathrm{N} 15$ & 0.03 & 0.1 \\
\hline $\mathrm{O} 1-\mathrm{C} 2$ & 0.3 & 0.35 & $\mathrm{C} 16-\mathrm{N} 15$ & 0.07 & 0.08 \\
\hline $\mathrm{O} 1-\mathrm{C} 9$ & 0.28 & 0.31 & \multicolumn{3}{|l|}{$\mathrm{C}-\mathrm{H}$ bond type } \\
\hline Conjugated $\mathrm{C}-\mathrm{C}$ bonds & & & $\mathrm{C} 3-\mathrm{H} 3$ & 0.26 & 0.23 \\
\hline $\mathrm{C} 3-\mathrm{C} 2$ & 0.21 & 0.17 & $\mathrm{C} 5-\mathrm{H} 5$ & 0.25 & 0.28 \\
\hline $\mathrm{C} 4-\mathrm{C} 3$ & 0.26 & 0.3 & \multicolumn{3}{|c|}{$\mathrm{C}-\mathrm{H} 2$ bond group } \\
\hline $\mathrm{C} 10-\mathrm{C} 4$ & 0.22 & 0.21 & $\mathrm{C} 12-\mathrm{H} 12 A$ & 0.24 & 0.25 \\
\hline $\mathrm{C} 10-\mathrm{C} 9$ & 0.21 & 0.25 & $\mathrm{C} 12-\mathrm{H} 12 B$ & 0.24 & 0.25 \\
\hline $\mathrm{C} 5-\mathrm{C} 6$ & 0.28 & 0.31 & $\mathrm{C} 13-\mathrm{H} 13 A$ & 0.23 & 0.25 \\
\hline $\mathrm{C} 10-\mathrm{C} 5$ & 0.23 & 0.26 & $\mathrm{C} 13-\mathrm{H} 13 B$ & 0.23 & 0.25 \\
\hline $\mathrm{C} 8-\mathrm{C} 9$ & 0.28 & 0.3 & $\mathrm{C} 14-\mathrm{H} 14 A$ & 0.24 & 0.24 \\
\hline $\mathrm{C} 6-\mathrm{C} 7$ & 0.21 & 0.22 & $\mathrm{C} 14-\mathrm{H} 14 B$ & 0.24 & 0.24 \\
\hline $\mathrm{C} 7-\mathrm{C} 8$ & 0.25 & 0.26 & $\mathrm{C} 16-\mathrm{H} 16 A$ & 0.24 & 0.24 \\
\hline Single $\mathrm{C}-\mathrm{C}$ bonds & & & $\mathrm{C} 16-\mathrm{H} 16 B$ & 0.24 & 0.24 \\
\hline $\mathrm{C} 6-\mathrm{C} 12$ & 0.14 & 0.13 & $\mathrm{C} 17-\mathrm{H} 17 A$ & 0.23 & 0.24 \\
\hline $\mathrm{C} 18-\mathrm{C} 8$ & 0.14 & 0.14 & $\mathrm{C} 17-\mathrm{H} 17 B$ & 0.23 & 0.25 \\
\hline $\mathrm{C} 16-\mathrm{C} 17$ & 0.12 & 0.13 & $\mathrm{C} 18-\mathrm{H} 18 A$ & 0.24 & 0.25 \\
\hline $\mathrm{C} 17-\mathrm{C} 18$ & 0.13 & 0.13 & $\mathrm{C} 18-\mathrm{H} 18 B$ & 0.25 & 0.25 \\
\hline $\mathrm{C} 4-\mathrm{C} 23$ & 0.16 & 0.15 & \multicolumn{3}{|c|}{$\mathrm{C}-\mathrm{H} 3$ of the methyl group } \\
\hline $\mathrm{C} 14-\mathrm{C} 13$ & 0.13 & 0.13 & $\mathrm{C} 23-\mathrm{H} 23 A$ & 0.31 & 0.31 \\
\hline $\mathrm{C} 13-\mathrm{C} 12$ & 0.12 & 0.13 & $\mathrm{C} 23-\mathrm{H} 23 B$ & 0.3 & 0.29 \\
\hline & & & $\mathrm{C} 23-\mathrm{H} 23 C$ & 0.32 & 0.3 \\
\hline
\end{tabular}

average). The $\mathrm{C} 12, \mathrm{C} 13$ and $\mathrm{C} 23$ atoms show significantly much more negative ELMAM2 $Q_{\text {Eflux }}$ charges; the average charge is -0.23 e calculated from the ELMAM2 parameters instead of $-0.08 \mathrm{e}$ in experimental results. Globally the two sets of $Q_{\text {Eflux }}$ charges show a correlation of $97.5 \%$, while $r=99.3 \%$ for the EXPML $Q_{\text {Eflux }}$ and $Q_{\text {AIM }}$ charges.

Comparison of the atomic forces in the C-102 EXPML and ELMAM2 library electron densities also shows similar overall trends, with a correlation coefficient reaching $98.3 \%$. The best agreement is indeed obtained for the $\mathrm{H}$ atoms where the discrepancy between the two calculations does not exceed $0.05 \mathrm{e}^{2} \AA^{-2}$. In the ELMAM2 model, high atomic forces are also calculated on the most asymmetrical atomic environments of electron density, i.e. O1, O11, C2, C7, C9, C14 and C16 atoms. The largest disagreements are observed on O11 and $\mathrm{C} 2$ atoms which reach 0.6 and $0.4 \mathrm{e}^{2} \AA^{-2}$ respectively.

Table 8 shows the interatomic forces calculated in the C-102 molecule. The bonds were classified by chemical similarities (single $\mathrm{C}-\mathrm{O}$, conjugated $\mathrm{C}-\mathrm{O}$, single $\mathrm{C}-\mathrm{C} \cdots$ ) for clarity. As expected from the atomic hybridization, the $\mathrm{C} 2=\mathrm{O} 11$

those of atoms involved in a $\sigma$ bond (non-polar). Hence, higher force moduli (1.59 and $0.91 \mathrm{e}^{2} \AA^{-2}$ respectively) are, as expected, observed for the carboxyl atoms O11 and $\mathrm{C} 2$ respectively. The $\mathrm{O} 1$ atom bonded to $\mathrm{C} 2$ and $\mathrm{C} 9$ is in a more symmetrical environment leading to a significant decrease of the resulting force $\left(0.53 \mathrm{e}^{2} \AA^{-2}\right)$. The same situation holds for $\mathrm{N} 15\left(0.23 \mathrm{e}^{2} \AA^{-2}\right)$ linked to three $\mathrm{C}$ atoms. The C7 and C9 atoms exhibit forces of 0.29 and $0.35 \mathrm{e}^{2} \AA^{-2}$ corresponding to the anisotropy of their chemical environments, i.e. connected to two $\mathrm{C}-\mathrm{C}$ bonds and a $\mathrm{C}-\mathrm{N}(\mathrm{C}-\mathrm{O})$ bond. $\mathrm{C} 10, \mathrm{C} 6, \mathrm{C} 4$ and $\mathrm{C} 8$ atoms which occur in most symmetrical environments display forces ranging from 0.06 to $0.13 \mathrm{e}^{2} \AA^{-2}$. Among the $\mathrm{Csp}^{3}$ atoms, only $\mathrm{C} 16$ exhibits a high force value of $0.25 \mathrm{e}^{2} \AA^{-2}$, while the other atomic forces range from 0.12 to $0.17 \mathrm{e}^{2} \AA^{-2}$. All the $\mathrm{H}$ atoms of $\mathrm{CH}$ or $\mathrm{CH}_{2}$ nature exhibit a total force ranging from 0.21 to $0.25 \mathrm{e}^{2} \AA^{-2}$. The methyl $\mathrm{H}$ atoms show, however, slightly greater forces $\left(0.31 \mathrm{e}^{2} \AA^{-2}\right.$ on average).

For comparison, Table 7 also lists the charges and total atomic forces obtained by the flux of the electric field through the atomic surface from C-102 ELMAM2 modelling. The overall behavior, as obtained from C-102 EXPML, in $Q_{\text {Eflux }}$ charge calculation is observed: i.e. the highest charges are obtained on the most electronegative atoms as expected. A larger discrepancy $(0.18 \mathrm{e})$ is however obtained on N15 and the most positive charges are obtained for $\mathrm{C} 7$ and $\mathrm{C} 9$ atoms. The agreement does not hold for $\mathrm{C} 14$ and $\mathrm{C} 16$ atoms (bound to a $\mathrm{N}$ atom), where neutral $Q_{\text {Eflux }}$ charges are calculated (0.02 e for both) from the ELMAM2 library. All the $\mathrm{H}$ atoms exhibit sensitively higher $Q_{\text {Eflux }}$ charges ( 0.13 e on average) in comparison with experimentally derived charges (0.04 e on conjugated bond exhibits the highest interatomic EXPML force $\left(1.18 \mathrm{e}^{2} \AA^{-2}\right)$. This value decreases to $0.30 \mathrm{e}^{2} \AA^{-2}$, on average, for the $\mathrm{C} 2-\mathrm{O} 1$ and $\mathrm{C} 9-\mathrm{O} 1$ single bonds. A significantly larger interatomic force is obtained in the $\mathrm{C} 7-\mathrm{N} 15$ bond $\left(0.16 \mathrm{e}^{2} \AA^{-2}\right)$ compared with the two other $\mathrm{C}-\mathrm{N}$ bonds (0.05 $\mathrm{e}^{2} \AA^{-2}$ on average). Similar interatomic force values ranging from 0.21 to $0.28 \mathrm{e}^{2} \AA^{-2}$ are obtained for the $\mathrm{C}-\mathrm{C}$ conjugated bonds. Consistency is also obtained on the $\mathrm{C}-\mathrm{C}$ and $\mathrm{C}-\mathrm{H}$ single bonds (the interatomic force average is 0.14 and $0.24 \mathrm{e}^{2} \AA^{-2}$ respectively). Higher interatomic force values are calculated on the $\mathrm{C}-\mathrm{H}$ methyl group $\left(0.30 \mathrm{e}^{2} \AA^{-2}\right.$ on average).

These interatomic force values are very similar to those reported in our previous work on piracetam (Chambrier et al., 2011). Table 8 also lists the results of interatomic forces in the C-102 ELMAM2 model. The only large discrepancy between the two models is related to the $\mathrm{C} 2=\mathrm{O} 11$ bond, which has an overestimated interatomic force in the ELMAM2 model (1.79 $\mathrm{e}^{2} \AA^{-2}$ rather than $1.18 \mathrm{e}^{2} \AA^{-2}$ obtained from C-102 EXPML). For all other bonds, very good agreement is obtained between the ELMAM2 library and experimental results, with an r.m.s. deviation of $0.025 \mathrm{e}^{2} \AA^{-2}$.

\section{Conclusion}

The present study provides an electron-density analysis in the solid state of the coumarin-102 dye. The use of low-temperature high-resolution X-ray diffraction data allowed a high quality charge-distribution model to be obtained. Topological analysis revealed the existence of the delocalization of the $\pi$ electron cloud of the chromen-2-one ring, which is in reso- 
nance with the $\mathrm{N}$ amino atom and indicated the existence of an intramolecular charge transfer. The dissymmetric character of the charge distribution generating a dipole moment along the molecule was also established. The substantial molecular dipole moment enhancement in the crystal environment is due to the crystal field and the intermolecular charge transfer induced and controlled by the intermolecular hydrogen-bond network.

Besides, the very satisfactory level of agreement observed between the experimental and ELMAM2 charge-density models strongly encourage the use of the database transfer approach in investigations of quantitative crystal engineering in the absence of high-resolution diffraction data.

The atomic basins calculated from Bader's (1990) atoms in molecules theory are used to obtain an estimation for the atomic charges and electrostatic total forces through the introduction of the Maxwell tensor. These atomic forces are conformation-dependent and reflect the bond hybridization and the local symmetry of electron density. They represent a measure of the deviation of the electron density from both chemistry-environmental and conformational symmetries. The atomic forces derived from the experimental and ELMAM2 charge-density parameters show globally similar trends. The largest discrepancies are obtained on the carboxyl $\mathrm{C}=\mathrm{O}$ atoms.

To bypass the symmetry effects, the interatomic forces between connected atoms were also calculated. These forces seem to be enhanced by a balance between the bond polarity and the $\pi$ electrons. The results obtained on single and conjugated $\mathrm{C}-\mathrm{C}$ bonds and also on $\mathrm{C}-\mathrm{H}$ bonds are very similar to those reported on the three polymorphic crystal forms of piracetam. Very good agreement is generally observed between the interatomic forces derived from experimental and ELMAM2 charge-density parameters.

YBMB thanks l'Agence Universitaire de la Francophonie (AUF) for a postdoctoral research grant and IUCr for financial support. The CNRS and CNRST are acknowledged for travel support.

\section{References}

Allen, F. H., Kennard, O., Watson, D. G., Brammer, L., Orpen, A. G. \& Taylor, R. (1987). J. Chem. Soc. Perkin Trans. 2, S1-19.

Altomare, A., Cascarano, G., Giacovazzo, C., Guagliardi, A., Burla, M. C., Polidori, G. \& Camalli, M. (1994). J. Appl. Cryst. 27, 435.

Atkins, R. L. \& Bliss, D. E. (1978). J. Org. Chem. 43, 1975-1980.

Bader, R. F. W. (1990). Atoms in Molecules: A Quantum Theory. Oxford: Clarendon Press.

Bader, R. F. W. (2007). J. Phys. Chem. A, 111, 7966-7972.

Barik, A., Kumbhakar, M., Nath, S. \& Pal, H. (2005). Chem. Phys. 315, 277-285.

Blessing, R. H. (1989). J. Appl. Cryst. 22, 396-397.

Bouhmaida, N., Bonhomme, F., Guillot, B., Jelsch, C. \& Ghermani, N. E. (2009). Acta Cryst. B65, 363-374.

Bouhmaida, N., Dutheil, M., Ghermani, N. E. \& Becker, P. (2002). J. Chem. Phys. 116, 6196-6204.

Bouhmaida, N. \& Ghermani, N. E. (2008). Phys. Chem. Chem. Phys. 10, 3934-3941.
Cave, R. J., Castner, E. W. Jr (2002). J. Phys. Chem. A, 106, 1211712123.

Chambrier, M. H., Bouhmaida, N., Bonhomme, F., Lebegue, S., Gillet, J. M., Jelsch, C. \& Ghermani, N. E. (2011). Cryst. Growth Des. 11, 2528-2539.

Chinnakali, K., Selladurai, S., Sivakumar, K., Subramanian, K. \& Natarajan, S. (1990). Acta Cryst. C46, 837-839.

Chinnakali, K., Sivakumar, K. \& Natarajan, S. (1989). Acta Cryst. C45, 1065-1066.

Chinnakali, K., Sivakumar, K. \& Natarajan, S. (1990a). Acta Cryst. C46, 405-407.

Chinnakali, K., Sivakumar, K. \& Natarajan, S. (1990b). Acta Cryst. C46, 669-671.

Chinnakali, K., Sivakumar, K. \& Natarajan, S. (1990c). Acta Cryst. C46, 833-835.

Chinnakali, K., Sivakumar, K., Natarajan, S. \& Mathews, I. I. (1992). Acta Cryst. C48, 386-387.

Clark, R. C. \& Reid, J. S. (1995). Acta Cryst. A51, 887-897.

Coppens, P. (1997). X-ray Charge Density and Chemical Bonding. New York: Oxford University Press.

Diraison, M., Millie, P., Pommeret, S., Gustavsson, T. \& Mialocq, J.-C. (1998). Chem. Phys. Lett. 282, 152-158.

Domagała, S. \& Jelsch, C. (2008). J. Appl. Cryst. 41, 1140-1149.

Domagała, S., Munshi, P., Ahmed, M., Guillot, B. \& Jelsch, C. (2011). Acta Cryst. B67, 63-78.

Drexhage, K. H. (1973). Topics in Applied Physics, edited by F. P. Schäfer, Vol. 1, pp. 144-193. New York: Springer-Verlag.

Espinosa, E., Souhassou, M., Lachekar, H. \& Lecomte, C. (1999). Acta Cryst. B55, 563-572.

Farrugia, L. J. (1997). J. Appl. Cryst. 30, 565.

Fletcher, A. N. \& Bliss, D. E. (1978). Appl. Phys. 16, 289-295.

Ghermani, N. E., Bouhmaida, N. \& Lecomte, C. (1992a). ELECTROS. Internal Report UMR CNRS 7036, Université Henri Poincaré, Nancy 1, France.

Ghermani, N. E., Bouhmaida, N. \& Lecomte, C. (1992b). STATDENS. Internal report CNRS 8612. Université Paris-Sud 11, France.

Ghermani, N. E., Bouhmaida, N. \& Lecomte, C. (1992c). FIELD. Université Cadi Ayyad, Morocco.

Ghermani, N. E., Lecomte, C. \& Bouhmaida, N. Z. (1993). Z. Naturforsch. A, 48, 91-98.

Glossman-Mitnik, D. (2009). J. Mol. Struct. Theochem, 911, 105-108. Görbitz, C. H. (1999). Acta Cryst. B55, 1090-1098.

Guillot, B. (2011). Acta Cryst. A67, C511-C512.

Guillot, B., Viry, L., Guillot, R., Lecomte, C. \& Jelsch, C. (2001). J. Appl. Cryst. 34, 214-223.

Gustavsson, T., Cassara, L., Gulbinas, V., Gurzadyan, G., Mialocq, J.C., Pommeret, S., Sorgius, M. \& van der Meulen, P. (1998). J. Phys. Chem. A, 102, 4229-4245.

Hansen, N. K. \& Coppens, P. (1978). Acta Cryst. A34, 909-921.

Hara, K., Sato, T., Katoh, R., Furube, A., Ohga, Y., Shinpo, A., Suga, S., Sayama, K., Sugihara, H. \& Arakawa, H. (2003). J. Phys. Chem. $B, \mathbf{1 0 7}, 597-606$.

Hara, K., Sayama, K., Ohga, Y., Shinpo, A., Suga, S. \& Arakawa, H. (2001). Chem. Commun. pp. 569-570.

Hara, K., Tachibana, Y., Ohga, Y., Shinpo, A., Suga, S., Sayama, K., Sugihara, H. \& Arakawa, H. (2003). Sol. Energy Mater. Sol. Cells, 77, 89-103.

Henkelman, G., Arnaldsson, A. \& Jónsson, H. (2006). Comput. Mater. Sci. 36, 354-360.

Hernández-Trujillo, J., Cortés-Guzmán, F., Fang, D.-C. \& Bader, R. F. W. (2007). Faraday Discuss. 135, 79-95.

Honda, T., Fujii, I., Hirayama, N., Aoyama, N. \& Miike, A. (1996). Acta Cryst. C52, 679-681.

Howard, J. A. K., Mahon, M. F., Raithby, P. R. \& Sparkes, H. A. (2009). Acta Cryst. B65, 230-237.

Jasinski, J. P. \& Woudenberg, R. C. (1994). Acta Cryst. C50, 19541956. 
Jasinski, J. P. \& Woudenberg, R. C. (1995). Acta Cryst. C51, 107-109.

Jelsch, C., Guillot, B., Lagoutte, A. \& Lecomte, C. (2005). J. Appl. Cryst. 38, 38-54.

Jones, G. II, Feng, Z. \& Bergmark, W. R. (1994). J. Phys. Chem. 98, 4511-4516.

Jones, G. II, Jackson, W. R., Choi, C.-Y. \& Bergmark, W. R. (1985). J. Phys. Chem. 89, 294-300.

Jones, G. II, Jackson, W. R. \& Konaktanaporn, S. (1980). Opt. Commun. 33, 315-320.

Kissel, L., Zhou, B., Roy, S. C., Sen Gupta, S. K. \& Pratt, R. H. (1995). Acta Cryst. A51, 271-288.

Kubicki, M., Borowiak, T., Dutkiewicz, G., Souhassou, M., Jelsch, C. \& Lecomte, C. (2002). J. Phys. Chem. 106, 3706-3714.

Kumar, P. V. \& Maroncelli, M. (1995). J. Chem. Phys. 103, 3038-3060.

Madsen, A. Ø. (2006). J. Appl. Cryst. 39, 757-758.

Marling, J. B., Hawley, J. G., Liston, E. M. \& Grant, W. B. (1974). Appl. Opt. 13, 2317-2320.

McKinnon, J. J., Spackman, M. A. \& Mitchell, A. S. (2004). Acta Cryst. B60, 627-668.

Morlet-Savary, F., Ley, C., Jacques, P. \& Fouassier, J. P. (2001). J. Phys. Chem. A, 105, 11026-11033.

Muhlpfordt, A., Schanz, R., Ernsting, N., Farztdinov, V. \& Grimme, S. (1999). Phys. Chem. Chem. Phys. 14, 3209-3218.

Munshi, P. \& Guru Row, T. N. (2005). J. Phys. Chem. A, 109, 659-672.

Munshi, P. \& Guru Row, T. N. (2006). Cryst. Growth Des. 6, 708-718.

Munshi, P., Jelsch, C., Hathwar, V. R. \& Guru Row, T. N. (2010). Cryst. Growth Des. 10, 1516-1526.

Nad, S., Kumbhakar, M. \& Pal, H. (2003). J. Phys. Chem. A, 107, 4808-4816.

Nad, S. \& Pal, H. (2001). J. Phys. Chem. A, 105, 1097-1106.

Novaković, S. B., Bogdanović, G. A., Fraisse, B., Ghermani, N. E., Bouhmaida, N. \& Spasojević-de Biré, A. (2007). J. Phys. Chem. A, 111, 13492-13505.

Oxford Diffraction (2009a). CrysAlis CCD, Version 1.171.33.42. Oxford Diffraction Ltd, Yarnton, Oxfordshire, England.

Oxford Diffraction (2009b). CrysAlis RED, Version 1.171.33.42. Oxford Diffraction Ltd, Yarnton, Oxfordshire, England.
Paul, A., Kubicki, M., Kubas, A., Jelsch, C., Fink, K. \& Lecomte, C. (2011). J. Phys. Chem. A, 115, 12941-12952.

Pichon-Pesme, V., Jelsch, C., Guillot, B. \& Lecomte, C. (2004). Acta Cryst. A60, 204-208.

Reynolds, G. A. \& Drexhage, K. H. (1973). Opt. Commun. 13, 222 225.

Sanville, E., Kenny, S. D., Smith, R. \& Henkelman, G. (2007). $J$. Comput. Chem. 28, 899-908.

Selladurai, S. \& Subramanian, K. (1992). Acta Cryst. C48, 281283.

Senthilkumar, S., Nath, S. \& Pal, H. (2004). Photochem. Photobiol. 80, 104-111.

Sheldrick, G. M. (2008). Acta Cryst. A64, 112-122.

Slater, J. C. (1932). Phys. Rev. 42, 33-43.

Spackman, M. A., Munshi, P. \& Dittrich, B. (2007). ChemPhysChem, 8, 2051-2063.

Spek, A. L. (2003). J. Appl. Cryst. 36, 7-13.

Stewart, R. F. (1982). God. Jugosl. Cent. Krystallogr. 17, 1-24.

Su, Z. \& Coppens, P. (1997). Acta Cryst. A53, 749-762.

Tuccio, S. A., Drexhage, K. H. \& Reynolds, G. A. (1973). Opt. Commun. 7, 248-252.

Volkov, A., Gatti, C., Abramov, Y. \& Coppens, P. (2000). Acta Cryst. A56, 252-258.

Volkov, A., King, H. F., Coppens, P. \& Farrugia, L. J. (2006). Acta Cryst. A62, 400-408.

Wang, Z. S., Hara, K., Dan-oh, Y., Kasada, C., Shinpo, A., Suga, S., Arakawa, H. \& Sugihara, H. (2005). J. Phys. Chem. B, 109, $3907-$ 3914.

Weber, H.-P. \& Craven, B. M. (1990). Acta Cryst. B46, 532-538.

Yip, B.-C., Fun, H.-K., Sivakumar, K., Zhou, Z.-Y., Shawkataly, O. B. \& Teoh, S.-G. (1995). Acta Cryst. C51, 956-958.

Yip, B.-C., Moo, F.-M., Lok, K.-S., Fun, H.-K. \& Sivakumar, K. (1996). Acta Cryst. C52, 477-481.

Yip, B.-C., Yaw, O.-L., Ong, L.-H., Fun, H.-K. \& Sivakumar, K. (1995). Acta Cryst. C51, 2087-2089.

Zarychta, B., Pichon-Pesme, V., Guillot, B., Lecomte, C. \& Jelsch, C. (2007). Acta Cryst. A63, 108-125. 